\title{
Consumo sustentável e inovação social: o caso da moeda social do Banco Palmas
}

\author{
Angelica Catarine da Mota Araújo, Verônica Macário de Oliveira e \\ Suzanne Érica Nóbrega Correia
}

\section{RESUMO}

O objetivo deste artigo é analisar elementos de inovação social que podem contribuir para promoção do consumo sustentável. Para tanto, foi realizado um estudo de caso da moeda social operacionalizada pelo Banco Palmas. Desse modo, utilizou-se o framework proposto por Araújo (2020). O Banco Palmas é considerado um caso emblemático de inovação social que favorece a satisfação das necessidades sociais em diversas áreas, inclusive as de consumo. A compreensão da inovação social a partir da perspectiva do consumo sustentável ressalta a importância de analisar novos formatos organizacionais caracterizados por estruturas inovadoras, inclusivas e sustentáveis. A moeda social desempenha um papel-chave nesse processo porque reorganiza a economia local e promove uma transformação social. Além disso, ela auxilia no acesso ao consumo, incentivando a valorização dos recursos e potencialidades locais, de forma a promover uma rede local de produtores e consumidores. Isso representa uma mudança social e cultural da comunidade por meio de processos participativos e de emancipação.

Palavras-chave: consumo sustentável; inovação social; moeda social; Banco Palmas.

\section{Sustainable consumption and social innovation: the case of Banco Palmas social currency}

\section{ABSTRACT}

This article aims to analyze elements of social innovation that can contribute to the promotion of sustainable consumption. To this end, a case study of the social currency operated by Banco Palmas was carried out. Thus, we used the framework proposed by Araújo (2020). Banco Palmas is considered a typical social innovation case that favors the satisfaction of social needs in several areas, including consumption. The understanding of social innovation from the perspective of sustainable consumption highlights the importance of analyzing the new organizational formats characterized by innovative, inclusive, and sustainable structures. The social currency plays a crucial role in this process because it reorganizes the local economy and promotes social transformation. It also assists in the access of consumption, encouraging the valorization of local resources and potentials, thus developing a local network of producers and consumers. It represents is a social and cultural change in the community through participatory and emancipation processes.

Keywords: sustainable consumption; social innovation; Palmas Bank; social currency.

Recebido em: 19/12/2019 Revisado em: 15/06/2020 Aprovado em: 31/07/2020

Check for updates
Angelica Catarine da Mota Araújo (iD),

Universidade Federal de Campina

Grande, Brasil

Mestra em Administração,

Universidade Federal de Campina

Grande

catarineangelica@gmail.com

Verônica Macário de

Oliveira (iD,

Universidade Federal de Campina Grande, Brasil

Doutora em Administração,

Universidade Federal de Pernambuco

Brasil

veronicamacario@gmail.com

Suzanne Érica Nóbrega

Correia (iD,

Universidade Federal de Campina

Grande, Brasil

Doutora em Administração,

Universidade Federal de Pernambuco,

Brasil

suzanne.enc@gmail.com 
Introdução

As discussões sobre o consumo sustentável estão em ascensão devido ao impacto que as práticas cotidianas de consumo exercem sobre a economia, a sociedade e o meio ambiente, o que as tornam insustentáveis diante da possibilidade de esgotamento dos recursos naturais. A degradação do meio ambiente, a inequidade na distribuição das riquezas produzidas e a necessidade de proteção do ecossistema são temas cruciais para garantir condições de sobrevivência tanto das gerações atuais quanto das gerações futuras. Por isso, há um esforço internacional em prol do consumo sustentável em face aos problemas da escala atual de consumo.

O consumo sustentável, em termos de definição, consiste em atividades de aquisição e uso de produtos e serviços que atendam às necessidades básicas e tragam melhorias na qualidade de vida da sociedade, ao mesmo tempo em que se minimiza o uso de recursos naturais e materiais tóxicos, bem como se reduz a geração de resíduos e emissão de poluentes ao longo do ciclo de vida, considerando as necessidades das gerações atuais sem comprometer o atendimento das necessidades das gerações futuras (Phipps et al., 2013; Quoquab, Mohammad, \& Sukari, 2019; Quoquab \& Mohammad, 2017). As dimensões principais são três, sendo elas: manutenção da qualidade de vida; proteção ambiental e a garantia das condições de sobrevivência das gerações futuras. Isso requer a existência de abordagens sistêmicas que direcionem para a adoção de estruturas sustentáveis que ancorem as práticas de consumo e que envolvam questões de poder, legitimidade, autoridade e priorização de ações. Conforme ressaltam Amorim e del Río (2019), quando se trata de discussões sobre sustentabilidade, deve-se reconhecer a presença da complexidade como parte do sistema, o que exige uma análise mais ampla e profunda com o intuito de obter um entendimento real do processo em si e das partes relacionadas.

Considerando que os problemas ambientais resultantes do consumo englobam práticas cotidianas para o provimento das necessidades básicas de alimentação, habitação, transporte e bens de consumo, formas alternativas de produção e consumo estão surgindo na sociedade através dos próprios indivíduos para produzir, consumir e economizar através de organizações sociais que possuem significados de propriedade, cooperação e senso de comunidade (Jaeger-Erben, Rückert-John, \& Schäfer, 2015; Reisch, Cohen, Thøgersen, \& Tukker, 2016). Tais organizações são identificadas como inovação social, pois são consideradas como alternativas mais eficientes, eficazes, sustentáveis e justas de satisfazer necessidades ainda não satisfeitas pelo setor público e privado (Lorek \& Spangenberg, 2014; Oliveira, Gomez, \& Correia, 2018). As inovações sociais provocam mudanças socioculturais que possibilitam aumentar a capacidade sociopolítica da sociedade e de acesso aos recursos (Lorek \& Spangenberg, 2014; Mehmood \& Parra, 2013; Seyfang, 2007) por meio de estruturas alternativas de produção e consumo.

Dentre as iniciativas de inovação social com potencial para promoção do consumo sustentável, destacam-se as cooperativas de alimentos, agricultura orgânica, moedas sociais, energia eólica, partilha de carros, 
plataformas de negociação e permuta (Jaeger-Erben et al., 2015; Seyfang, 2010). No Brasil, especificamente, as moedas sociais operacionalizadas por Bancos Comunitários de Desenvolvimento (BCD) têm se difundido e causado impactos positivos em termos de inovação social para o consumo sustentável. Eles atuam a partir de práticas de finanças solidárias que facilitam o acesso ao crédito e oferecem diversos serviços financeiros aos moradores de determinadas comunidades (Rigo \& França, 2017) e possibilitam o acesso ao consumo. O Banco Palmas foi o primeiro BCD implantado no Brasil em 1998 com o propósito de fortalecer o desenvolvimento da comunidade Conjunto Palmeiras (Fortaleza - CE), a partir de uma rede de produção e consumo local baseadas nos princípios da Economia Solidária.

Nesse contexto, considera-se que as moedas sociais se caracterizam como uma inovação social, uma vez que elas são criadas e implementadas pela comunidade, com o propósito de apoiar a resolução de problemas sociais e econômicos, circular internamente, estimular a produção e o consumo no território, além de gerar riqueza para o desenvolvimento local (Rigo \& França, 2017). Isso corrobora com a definição de inovação social, que tem o propósito de solucionar problemas sociais para suprir necessidades de uma comunidade em áreas de consumo, habitação, educação, saúde e emprego (Cloutier, 2003; Howard, 2019; Tardif \& Harrisson, 2005).

Apesar do aumento no número de estudos sobre a temática de Consumo Sustentável e Inovação Social nos últimos anos, permanece uma lacuna nos estudos sobre as potencialidades das iniciativas de inovação social auxiliarem na promoção do consumo sustentável (Atrek \& ílter, 2017; Jaeger-Erben et al., 2015) em contextos específicos.

Diante do exposto, o objetivo deste artigo é analisar elementos de inovação social que podem contribuir para promoção do consumo sustentável. Para tanto, foi realizado um estudo de caso da moeda social operacionalizada pelo Banco Palmas. Desse modo, utilizou-se o framework proposto por Araújo (2020) que avançou nas discussões sobre inovações sociais para o consumo sustentável através da identificação dos elementos que podem operacionalizar novas formas de organização, produtos, serviços e práticas que podem mudar as estruturas que ancoram as práticas de consumo em contextos específicos. A abordagem da pesquisa é qualitativa e de natureza exploratória e descritiva. A escolha desse caso empírico ocorreu devido ao fato de o Banco Palmas ser referência nacional e reconhecido internacionalmente, sendo também o primeiro banco comunitário criado no Brasil, o que o torna um caso emblemático a ser investigado.

O trabalho está dividido em cinco seções. Além desta introdução, apresenta-se o referencial teórico que aborda as discussões sobre o consumo sustentável. Posteriormente, o framework com os elementos da inovação social que podem contribuir para promoção do consumo sustentável é destacado. Na sequência, detalham-se os procedimentos metodológicos, seguidos das análises e discussão dos resultados. Por fim, tem-se as conclusões, destacando as implicações e direções futuras de pesquisas. 


\section{O Consumo sustentável como um desafio sistêmico e a importância da participação do Estado, do mercado e da sociedade}

Os padrões insustentáveis de produção e consumo foram reconhecidos como uma das principais causas de deterioração ambiental desde a Conferência do Rio em 1992 e, mais recentemente, foi incluído como um dos Objetivos do Desenvolvimento Sustentável (ODS) - Agenda 2030. Nessa Agenda Global, o objetivo 12 especificamente visa assegurar padrões de produção e de consumo sustentáveis para a redução da pegada ecológica sobre o meio ambiente, cujas metas são: a promoção da eficiência do uso de recursos energéticos e naturais; promover uma infraestrutura sustentável; possibilitar acesso a serviços básicos, entre outras (Colglazier, 2015).

Os impactos ambientais estão diretamente associados ao volume de produção e consumo devido ao uso excessivo dos recursos naturais. Assim, se faz necessário a redução destes volumes para reestruturar os atuais modos de produção e consumo da sociedade (Bengtsson, Alfredsson, Cohen, Lorek, \& Schroeder, 2018), evidenciando a necessidade de mudança de paradigma do hábito de consumo convencional para o comportamento de consumo sustentável (Quoquab et al., 2019).

Porém, esse aspecto só é válido quando se considera os que têm acesso aos recursos, pois não se pode deixar de considerar também o fato de que muitas pessoas continuam sem ter suas necessidades de consumo atendidas pelo mercado convencional. Nessa perspectiva, torna-se relevante conhecer quais são as alternativas que surgem na sociedade que possibilitam acesso ao consumo e ao suprimento de necessidades básicas da população (Oliveira et al., 2018).

O conceito de consumo sustentável propõe manter um equilíbrio intra e inter geracional, e não se limita a mudanças individuais no comportamento do consumidor ou de melhorias tecnológicas nos processos produtivos (Jackson, 2007; Oliveira et al., 2018). A ideia principal é abranger ações coletivas e mudanças políticas, econômicas e institucionais, ou seja, um esforço coletivo em prol deste objetivo (Di Giulio et al., 2019; Oliveira et al., 2018; Tukker et al., 2008). Entretanto, ainda não há consenso sobre uma definição precisa do termo consumo sustentável, ou sobre o domínio de aplicação do conceito (Jackson, 2007; Quoquab et al., 2019). Por tratar-se de um fenômeno complexo, uma interação entre diversos atores da sociedade é necessária: com o governo, as empresas e a sociedade, assumindo responsabilidade para enfrentar os desafios da proposta (Di Giulio et al., 2019; Kiss, Pataki, Koves, \& Kiraly, 2018; Reisch et al., 2016; Schroder et al., 2019; Tukker et al., 2008).

Alguns dos principais entraves para alcançar o consumo sustentável estão relacionados a fatores como: características da própria sociedade atual e os seus padrões de consumo; dificuldades que envolvem questões de mudança pessoal e ameaças a uma ampla gama de interesses que estão subjacentes para alcançá-lo (Jackson \& Michaelis, 2003). Além do mais, percebe-se que há uma ausência de comprometimento com estratégias direcionadas ao consumo sustentável, devido a uma falha na governança 
global e de interesses conflitantes para o processo de mudança requerido (Fuchs \& Lorek, 2005).

Assim, a necessidade de mudança na cultura de consumo requer a atuação em escala tanto individual quanto coletiva, como um exercício de cidadania, levando em consideração que as práticas de consumo impactam na sociedade, na economia e no meio ambiente (Costa \& Teodósio, 2011; Jackson, 2007). Isso requer uma mobilização de atores sociais, organizacionais e institucionais que está se refletindo na Agenda 2030 mundial de ações a serem implantadas para alcançar o que se almeja em termos de sustentabilidade das práticas de consumo.

Algumas iniciativas advindas da sociedade têm provocado mudanças estruturais que têm potencial contribuição para o consumo sustentável, dentre as quais destacam-se as inovações sociais que podem promover o consumo sustentável através de alguns elementos fundamentais que serão apresentados na seção a seguir.

\section{A inovação social para o consumo sustentável}

Desde que as soluções tradicionais têm se mostrado insuficientes para resolver problemas sociais diversos, o campo da Inovação Social (IS) tem recebido atenção crescente no ambiente acadêmico, político e gerencial nos últimos tempos (Domanski, Howaldt, \& Kaletka, 2019; Kaya Özbag, Esen, \& Esen, 2019). A expressão "inovação social" passou a ser utilizada na década de 1960 e início dos anos de 1970, inicialmente voltada a movimentos sociais estudantis e dos trabalhadores de cidades europeias e americanas, com foco em ações coletivas para uma transformação social (Moulaert, Martinelli, Gonzalez, \& Swyngedouw, 2007). O primeiro pesquisador a usar o termo "inovação social" foi Taylor, em 1970, e Gabor também no mesmo ano, de modo a contribuir para o tema através de uma perspectiva do desenvolvimento de território (Cloutier, 2003).

A expansão das discussões e do entendimento sobre inovação social ocorreu a partir da década de 1990 (BEPA, 2010). Desde então, há um exponencial crescimento de publicações científicas sobre o tema, com impulso evidente a partir do ano de 2015 (Kaya Ozbag et al., 2019) devido ao potencial da inovação social para lidar com desafios sociais, econômicos, políticos e ambientais contemporâneos (Deserti \& Rizzo, 2019; Domanski et al., 2019; Hervieux \& Voltan, 2019).

A inovação social tem se destacado como um novo paradigma de inovação, cuja lógica centra-se no aspecto social, colaborativo e participativo que gera empoderamento e inclusão social (Domanski et al., 2019; Pel, Wallenborn, \& Bauler, 2016). A inovação social busca a satisfação das necessidades humanas através de alternativas que solucionem problemas sociais que não são contemplados nos segmentos públicos e privados (Nunes, Casagrande, Ramos, Santos, \& Corseuil, 2017). Ou seja, "inovações sociais são inovações que são sociais em seus fins e em seus meios" (Huysentruyt, Bulakowskiy, \& Ramsden, 2013, p. 6).

Nesse sentido, são identificadas como iniciativas que geram inclusão social, as mudanças nas relações sociais, a geração de novas ideias 
desenvolvidas por diferentes atores, o empoderamento e a emancipação de indivíduos desfavorecidos na sociedade (Agostini, Vieira, \& Bossle, 2016). Desse modo, trata-se de um processo de construção social em que só faz sentido se ocorrer a participação e a cooperação entre os atores (Howaldt \& Schwarz, 2017; Nunes et al., 2017).

A literatura sobre a temática aponta algumas iniciativas de inovação social que têm apresentado alternativas de produção e consumo por meio de organizações, produtos, serviços e práticas que têm criado novas soluções em respostas aos desafios atuais (Jaeger-Erben et al., 2015). Dentre alguns exemplos, destacam-se as cooperativas de alimentos, agricultura orgânica, moedas sociais, energia eólica, partilha de carros, plataformas de negociação e permuta (Jaeger-Erben et al., 2015; Lorek \& Spangenberg, 2014; Mont et al., 2014).

Para analisar a contribuição efetiva dessas iniciativas para o consumo sustentável, tornou-se necessário identificar os elementos e as relações estabelecidas, estudo este que foi realizado por Araújo (2020) mediante pesquisa de validação realizada com especialistas brasileiros cujo resultado é apresentado no framework disposto na Figura 1.

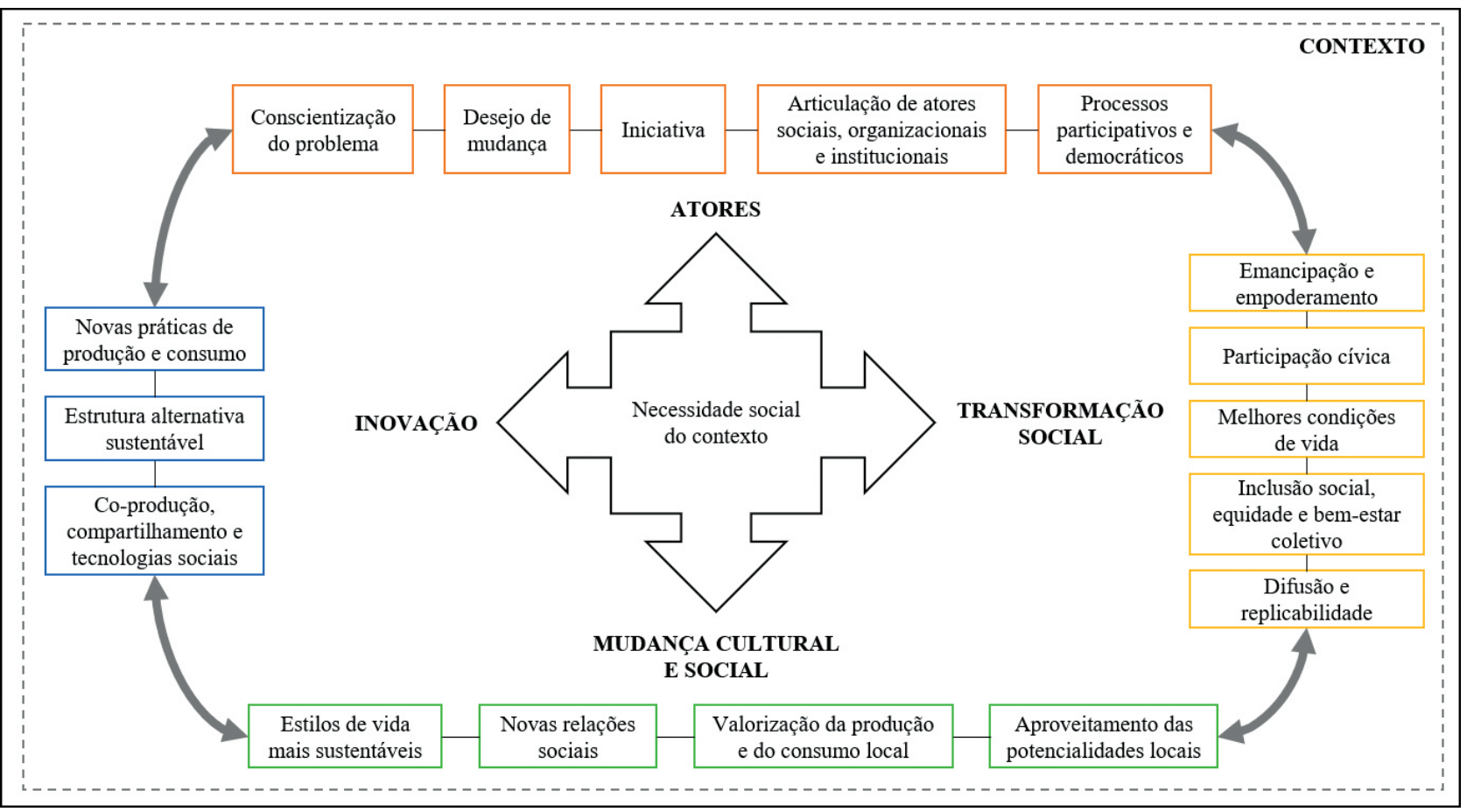

Figura 1. Framework elementos da inovação social que podem contribuir para a promoção do consumo sustentável Fonte: Araújo (2020)

Os principais elementos do framework são: Atores, Inovação, Mudança Cultural e Social, Transformação Social e a necessidade social do contexto como elemento central do processo. A necessidade social impulsiona os indivíduos a uma urgência na busca de uma mudança no contexto social (André \& Abreu, 2006; Di Giulio et al., 2019; Rollin \& Vincent, 2007), buscando soluções para problemáticas relacionadas ao desemprego, desigualdade de renda, degradação ambiental, exclusão e marginalização social (Howaldt, Domanski, \& Kaletka, 2016; Tardif \& Harrisson, 2005). 
Os indivíduos envolvidos nas iniciativas de inovação social são os atores sociais que se conscientizam do problema e desejam uma mudança diante de um contexto marcado de problemáticas sociais. A iniciativa é tomada para a articulação com outros atores organizacionais e institucionais, por meio de processos participativos e democráticos que buscam soluções de forma coletiva (Cloutier, 2003; Correia, Oliveira, \& Gomez, 2016; Howaldt, Domanski, \& Kaletka, 2016; Nunes et al., 2017; Tardif \& Harrisson, 2005).

A dimensão Inovação possui como categorias de análise as novas práticas de produção e consumo fora do mercado convencional ao criar uma estrutura alternativa sustentável, visando o atendimento das necessidades básicas da comunidade, que pode ser através da coprodução, compartilhamento de recursos, conhecimento e habilidade para o desenvolvimento de tecnologias sociais que objetivam a redução dos impactos socioambientais (Jaeger-Erben et al., 2015; Oliveira et al., 2018).

A dimensão Mudança cultural e social ressalta as atitudes e comportamentos que apresentam mudanças para estilos de vida mais sustentáveis. Novas relações sociais são estabelecidas com base na confiança, solidariedade, colaboração e comprometimento (Correia et al., 2016; Jaeger-Erben et al., 2015, 2017). Há um incentivo para uma valorização da produção e do consumo local e o aproveitamento das potencialidades e capacidades locais (Oliveira et al., 2018).

A dimensão Transformação social implica uma mudança social no contexto com novas orientações socioculturais, práticas e hábitos que apresentam novas perspectivas de vida para os indivíduos (Bouchard, 2012). A transformação gera inclusão social, emancipação e empoderamento dos envolvidos (Nunes et al., 2017; Pel, Wallenborn, \& Bauler, 2016), que passam a ter uma participação cívica presente na sociedade, buscando melhores condições de vida, equidade e bem-estar coletivo. A difusão e replicabilidade refere-se à disseminação e crescimento da inovação social para alcançar outros contextos e atender necessidades diversas (Caulier-Grice, Davies, Patrick, \& Norman, 2012; Mulgan, Tucker, Ali, \& Sanders, 2007; Murray, Caulier-Grice, \& Mulgan, 2010; Rollin \& Vincent, 2007).

Destarte, considera-se que a contribuição da inovação social reside no desenvolvimento de novos produtos, serviços ou modelos de negócios que produzem resultados efetivos (Piccarozzi, 2017) baseados nas necessidades e desafios atuais envolvendo mudanças nas relações sociais e no aumento da capacidade sociopolítica da população (Mehmood \& Parra, 2013). Tais elementos foram utilizados como base para a realização da presente pesquisa. Sendo assim, a seguir, delineamos os procedimentos metodológicos adotados.

\section{Drocedimentos metodológicos}

O objetivo deste artigo é analisar os elementos de inovação social que podem contribuir para promoção do consumo sustentável. Para tanto, foi realizado um estudo de caso da moeda social operacionalizada pelo Banco Palmas. Desse modo, utilizou-se o framework proposto por Araújo (2020). 
A pesquisa realizada foi de natureza qualitativa, ao considerar que o interesse está na compreensão do processo em que acontece o fenômeno e na dinâmica das relações sociais (Creswell, 2010; Larrinaga, 2017), explorando as condições da vida real do ponto de vista dos participantes e aspectos da realidade social que não podem ser quantificados (Creswell, 2010; Larrinaga, 2017; Yin, 2016). Quantos aos fins, configura-se como pesquisa exploratória e descritiva que visa se aprofundar sobre um tema para melhor compreensão do fenômeno investigado (Creswell, 2010; Sampieri, Collado, \& Lucio, 2014), buscando um novo enfoque ou abordagem teórica sobre o tema.

Quanto aos meios, adotou-se a estratégia de estudo de caso que consiste em uma pesquisa empírica que tem como propósito analisar um fenômeno contemporâneo, considerando o contexto em que está sendo estudado (Yin, 2016). O Banco Palmas foi selecionado como um caso que proporciona maior riqueza de dados por ser emblemático no Brasil e reconhecido internacionalmente como o primeiro Banco Comunitário de Desenvolvimento do país que deu início ao uso de moedas sociais. O critério de escolha dos respondentes ocorreu a partir da sua identificação e relação como ator social chave envolvido na iniciativa de inovação social do Banco Palmas. Para tanto, utilizou-se a técnica bola de neve (snowball), na qual os próprios entrevistados indicam outros representantes que possuem informações suficientes para alcançar o objetivo da pesquisa (Vinuto, 2014). A identificação dos entrevistados está descrita na Tabela 1.

Tabela 1: Identificação dos entrevistados

\begin{tabular}{|c|c|c|c|c|}
\hline Função* & Descrição de atividades & Identificação & Data & Tempo \\
\hline Fundador do Banco Palmas & $\begin{array}{l}\text { Um dos idealizadores do Banco } \\
\text { Palmas que está desde a criação. } \\
\text { Possui experiência de mais de } 35 \\
\text { anos de atuação no bairro. }\end{array}$ & $\mathrm{E} 1$ & 24/08/2019 & $1 \mathrm{~h} 30$ \\
\hline Coordenadora do e-dinheiro & $\begin{array}{l}\text { Faz o acompanhamento da moeda } \\
\text { social e-dinheiro e manutenção } \\
\text { diária do correspondente bancário. } \\
\text { Atuante no Banco Palmas há mais } \\
\text { de } 20 \text { anos. }\end{array}$ & E2 & 23/08/2010 & $1 \mathrm{~h} 44$ \\
\hline $\begin{array}{l}\text { Coordenadora da Associação } \\
\text { Mulheres Emancipadas, Presidente } \\
\text { da PalmaCoop e Coordenadora da } \\
\text { Cooperativa Prato Colorido }\end{array}$ & $\begin{array}{l}\text { Responsável por associações } \\
\text { e cooperativas relacionadas ao } \\
\text { Banco Palmas, atuante há } 7 \text { anos } \\
\text { nas ações, projetos e eventos } \\
\text { promovidos pelo Banco. }\end{array}$ & E3 & 22/08/2019 & $1 \mathrm{~h} 10$ \\
\hline Moradora do bairro & $\begin{array}{l}\text { Trabalha na Associação Mulheres } \\
\text { Emancipadas que é uma cozinha } \\
\text { comunitária que tem como objetivo a } \\
\text { geração de trabalho e renda para as } \\
\text { mulheres de baixa renda. }\end{array}$ & E4 & 23/08/2019 & $00: 23$ \\
\hline
\end{tabular}

Fonte: Dados da pesquisa, 2019.

* Todos os entrevistados, além das funções que exercem na comunidade, são moradores do bairro. 
Para a coleta de dados, utilizaram-se as seguintes técnicas: 1) a pesquisa documental para o levantamento dos dados secundários (artigos, vídeos, fotos, informativos, websites) sobre o Banco Palmas; 2) entrevistas semiestruturadas com os atores-chave identificados por meio da técnica bola de neve, utilizando as categorias de análise do framework proposto por Araújo (2020); 3) e a observação não-participante para melhor compreender a dinamicidade do fenômeno e o contexto em que está inserido. O período de pesquisa de campo, com visita in loco para observação não participante e as entrevistas ocorreram de 22 a 24 de agosto de 2019.

As entrevistas seguiram um roteiro semiestruturado construído a partir das dimensões do framework apresentado por Araújo (2020) com os elementos da inovação social que podem contribuir para promoção do consumo sustentável. A quantidade de entrevistas foi definida quando atingiu o ponto de saturação de modo que tornou possível responder ao objetivo que esta pesquisa se propôs, conforme se estabelece na técnica bola de neve (snowball).

Para o tratamento e análise dos dados, adotou-se o método de análise de conteúdo com mecanismos de codificação e categorização propostos por Bardin (2011). O objetivo foi tornar possível a descrição e interpretação do conteúdo de forma sistemática, com a finalidade de categorizá-la. A codificação permite que os dados sejam segregados, agrupados, reagrupados e relacionados, permitindo o pesquisador organizar os materiais coletados agrupando dados codificados dentro de categorias (Sampieri, Collado, \& Lucio, 2014). Para tanto, foi escolhida a lente analítica do tipo descritiva que resume em uma palavra ou uma frase curta um tópico da passagem de um dado qualitativo, com categorias pré-definidas a fim de buscar causas e explicações dos dados coletados. Posteriormente, foi aplicada a codificação por padrão para reorganizar e reanalisar os dados codificados do primeiro ciclo (Saldaña, 2013).

A ferramenta de apoio às análises foi o software de pesquisa qualitativa ATLAS.ti, para garantir maior sistematicidade na análise dos dados, estruturando os dados qualitativos de forma a auxiliar na organização das categorias de análise e na formação redes. Tais redes são associações, nas quais podem ser visualizadas as conexões existentes entre as informações codificadas (Sampieri et al., 2014).

Além disso, ressalta-se que a presente pesquisa seguiu os critérios de validade e confiabilidade sugeridos por Larrinaga (2017). A validade diz respeito à transparência na pesquisa e responsabilidade no tratamento das informações obtidas; outrossim, foi realizada uma comparação sistemática da literatura (Larrinaga, 2017). Em relação aos critérios de confiabilidade, utilizou-se software ATLAS.ti para análise dos dados que permitiu a organização, integração e sintetização das informações obtidas das diferentes fontes de evidências. De forma análoga, houve também um compromisso ético no esforço, tempo, dedicação e atividades em cada fase da pesquisa (Larrinaga, 2017). Por fim, realizou-se a triangulação entre as técnicas de coleta de dados para garantir a confiabilidade da pesquisa, cruzando dados da análise documental, entrevistas e observação não-participante.

Os resultados obtidos são apresentados e discutidos na seção a seguir. 
Contextualização do Banco Palmas e da moeda social: do PalmaCard ao e-dinheiro

O Banco Palmas foi fundado em 1998 na periferia de Fortaleza (CE), localizado no Conjunto Palmeiras, na região Nordeste do Brasil. Foi o primeiro no Brasil em aplicar o conceito de Banco Comunitário de Desenvolvimento (BCD) que é "um serviço financeiro, solidário, em rede, de natureza associativa e comunitária, voltado para reorganização das economias locais, na perspectiva da geração de trabalho e renda e da Economia Solidária" (Banco Palmas, 2010, p. 8).

A atuação do Banco Palmas baseia-se nos princípios da economia solidária que promove alternativas para modos de produção, distribuição e consumo que são geridos com a participação e o compromisso dos cidadãos (Moulaert et al., 2010). É, portanto, um processo de organização econômica, com responsabilidades compartilhadas e de forma democrática, apresentando um compromisso social, econômico e ambiental. Assim, pode ser considerado um exemplo de experiências de economia solidária, pois é um tipo de iniciativa que apresenta diferentes fontes de financiamento, tais como a moeda social, crédito para a produção e consumo, empréstimos, entre outros, cuja operação e controle ocorrem de forma local. A moeda social é uma moeda complementar ao real do Brasil e foi criada pelos Bancos Comunitários que oferecem empréstimos em pequenas quantidades em reais, bem como em moeda social que circula localmente.

Para entender o contexto social do Conjunto Palmeiras na época em que o Banco Palmas foi criado, se faz necessário remeter a década de 1970 quando a Prefeitura de Fortaleza removeu 1,5 mil famílias que estavam localizadas em áreas de risco que, na época de cheias, inundavam as habitações, pois eram também áreas de expansão urbana. Na década de 1980 a 1990 iniciaram a intensa mobilização popular para o processo de urbanização do bairro (Melo \& Magalhães, 2007), pois quando houve o remanejamento das famílias, o Conjunto Palmeiras ainda não possuía uma infraestrutura mínima de moradia.

Em 1997 o bairro estava urbanizado e com serviços básicos já instalados, no entanto, com a urbanização vieram as taxas de luz, água, esgoto, IPTU e os moradores não estavam conseguindo pagar, pois muitos estavam desempregados ou em subempregos. Por essa razão, esses moradores venderam suas casas, indo morar nas periferias da cidade (Melo \& Magalhães, 2007). Nesse cenário, várias discussões foram levantadas para reverter essa situação e manter os moradores que construíram o bairro a permanecer no Conjunto Palmeiras. Para tanto, era necessário um projeto que gerasse trabalho e renda ao mesmo tempo que estimulasse a produção e o consumo local. Dessa maneira, os moradores decidiram criar um banco popular e o cartão de crédito PalmaCard para atender a essa necessidade procedente de um contexto de marginalização e de extrema pobreza (Melo \& Magalhães, 2007).

A primeira experiência de moeda social criada em paralelo com o Banco Palmas foi chamada PalmaCard, que era em formato de cartão de crédito e circulava localmente, possibilitando o consumo de produtos e serviços 
no bairro (Melo \& Magalhães, 2007). Devido às novas necessidades que surgiram e que precisavam de adaptações à dinâmica socioeconômica, o PalmaCard foi substituído por outros formatos de moeda. Dentro dos clubes de trocas, a moeda que circulava era chamada de Palmares e Palmirins, ou seja, quando os produtores não conseguiam vender seus produtos no mercado, eles comercializam dentro desses clubes por meio dos Palmares (Melo \& Magalhães, 2007).

Com a consolidação do Banco e da credibilidade conquistada, posteriormente houve a introdução da moeda social em papel chamada de Palmas, que no decorrer dos anos assumiu novos formatos e modelos para se adequar às novas demandas sociais. De acordo com o Instituto Palmas (2019), a emissão de Moedas Sociais Locais Circulantes deve seguir as seguintes orientações: a) ser lastreada em moeda nacional (real); b) ser indexada ao real; c) permitir o câmbio (moeda social $x$ real $x$ moeda social); d) ter circulação restrita ao território de atuação do Banco Comunitário (não mais que 60.000 hab.); e) ser de livre aceitação pelos moradores e comércio local; f) não deve ser cobrado juros para empréstimo em moeda social; g) na frente da moeda deve ter o nome e endereço da entidade gestora do banco; h) no verso da moeda deve ter um texto explicativo de que se trata de um "bônus" que promove o desenvolvimento local e de uso exclusivo para troca de produtos e serviços na comunidade.

Devido à necessidade de modernização do sistema financeiro dos Bancos Comunitários, em 2015 o Banco Palmas passou a atuar como um banco digital e com uma moeda social eletrônica chamada e-dinheiro, que nasceu da adaptação das leis de pagamentos eletrônicos que contribuiu para a evolução das moedas sociais. A moeda eletrônica foi regulamentada pelo Banco Central, em 2013, para fomentar a inclusão financeira (Lei no. 12.865/13). O e-dinheiro é uma moeda social eletrônica, operacionalizada por meio de um celular smartphone através da instalação de um aplicativo desenvolvido para essa finalidade (Instituto Banco Palmas, 2019; Oliveira, 2019). Ou seja, é um novo meio de pagamento digital para facilitar as transações financeiras que continua a fomentar o comércio local, cuja gestão passa pelo controle dos bancos comunitários. Desta forma, amplia-se a fonte de receitas por meio das operações que ocorrem dentro do aplicativo, no qual uma taxa de porcentagem de todas as operações retorna para o Banco (Oliveira, 2019). Os serviços oferecidos pelo e-dinheiro são: abertura de conta corrente; transferências entre contas; depósitos; pagamento de boleto e faturas; cobranças; extratos da conta; controle dos gastos; compras no comércio local; recarga de celular; compra de seguros e pequenos empréstimos (Instituto Banco Palmas, 2019).

A moeda social eletrônica (e-dinheiro) possibilita também que as trocas comerciais sejam realizadas tanto internamente quanto externamente, o que amplia as possibilidades de geração de receitas que são revertidas em benefício da comunidade e dos Bancos Comunitários. Para atender às necessidades atuais dos moradores do bairro e adjacências, foi criado recentemente o cartão de crédito E-dinheiroCred para fortalecer o consumo no comércio local. Atualmente, existem mais de cem Bancos Comunitário de Desenvolvimento localizados em vários estados brasileiros, com uma concentração maior na região nordeste (Rigo \& França, 2017). 
O caso do Banco Palmas mostrou que apesar de ter sido oriundo de uma população marginalizada e desprovida de acessos e recursos, a iniciativa foi socialmente inovadora para criar o Banco Comunitário e uma moeda social para beneficiar os moradores e contribuir para o desenvolvimento da região (Melo \& Magalhães, 2007).

Vale ressaltar que se trata de uma ideia completamente endógena através do protagonismo dos moradores, líderes locais e membros da Associação dos Moradores do Conjunto Palmeiras (ASMOCONP), que buscavam melhorias na condição de vida da população (Melo \& Magalhães, 2007), sendo possível por meio da inserção de uma moeda social que transformou o cenário econômico, político e social da região.

O aspecto "social" está na natureza, no processo e na finalidade, pois a gestão das atividades e recursos são organizados e fiscalizadas pela própria comunidade (Bataglin, 2017), tornando os moradores partícipes em todo processo de gestão e implantação da inovação social, tal como preconiza a literatura da área. O Banco Palmas completou, em janeiro de 2019, 20 anos de atuação, e "[...] já movimentou $R \$ 23$ milhões em crédito e transações de consumo local no Conjunto Palmeiras. Ele também já atendeu a 5.600 microempreendimentos, beneficiando cerca de 30 mil pessoas em suas duas décadas de existência" (Serpa, 2018), reforçando, assim, o impacto gerado por essa iniciativa de inovação social através da moeda social.

\section{Verificação empírica dos elementos do framework aplicado no Banco Palmas-CE}

O objetivo deste artigo foi analisar elementos de inovação social que podem contribuir para promoção do consumo sustentável. Para tanto, foi utilizado o framework que apresenta os seguintes elementos: Atores, Inovação, Mudança Cultural e Social e Transformação Social, tendo como elemento central a necessidade social do contexto. Os resultados são analisados a seguir.

\section{Dimensão atores}

A dimensão "Atores" aborda os indivíduos envolvidos na geração de soluções para problemáticas sociais caracterizados como agentes de desenvolvimento local. As categorias de análise foram: "conscientização do problema"; "desejo de mudança"; "iniciativa"; "articulação de atores sociais, organizacionais e institucionais" e; "processos participativos e democráticos".

Os moradores do denominado Conjunto Palmeiras, mediante a remoção, pela prefeitura, da área urbana de Fortaleza - CE, para um local que não possuía uma infraestrutura urbana, ou seja, sem condições básicas de moradia, água, luz, esgoto (Melo \& Magalhães, 2007), enfrentaram inúmeros problemas sociais, econômicos e ambientais. Nesse contexto, passaram a buscar, conjuntamente, soluções para a situação em que se encontravam por meio de uma organização comunitária através de reuniões e assembleias realizadas com os moradores da região, valorizando a pluralização de ideias 
para a resolução dos problemas mediante processos participativos e democráticos. Assim, em 1981, foi criada a Associação dos Moradores do Conjunto Palmeiras (ASMOCONP) uma associação que até hoje é atuante na região e que tem contribuído para atender às demandas da população e se articulado para buscar melhorias para o bairro.

Em relação ao Banco Palmas, especificamente, foi criado em 1998, a partir da articulação dos moradores e líderes locais do Conjunto Palmeiras, o que se caracteriza como uma experiência de inovação social pautada na lógica de cooperação, solidariedade e organização popular para buscar melhores condições de vida para todos. A necessidade social que impulsionou a criação de um Banco Comunitário de Desenvolvimento (BCD) foi devido ao contexto de extrema pobreza, miséria e marginalização que os moradores do Conjunto Palmeiras se encontravam. O propósito foi reorganizar a economia local para gerar trabalho e renda. Uma característica dos moradores da região é a não conformação com o estado de pobreza, como pode ser observado na fala de um dos entrevistados.

\begin{abstract}
Os maiores valores de uma comunidade hoje não é nem o que ela tem de ativos, como o próprio Banco Palmas, quanto ele tem de dinheiro, quanto crédito ele já fez, o que ele atingiu, é que ele passou essa cultura para as pessoas de não aceitarem a pobreza, a miséria, a desigualdade como condição de vida, e essa indignação é profética, ela busca soluções, ela busca se organizar (Entrevistado E1).
\end{abstract}

Os moradores não esperaram uma solução vir de fora, mas um aspecto em comum era o desejo de mudança e com isso tiveram a iniciativa de buscar alternativas frente aos desafios presentes, conforme enfatizou o E2 ao afirmar que "a gente sabe que muita coisa depende de governo, mas muita coisa depende da gente". O que corrobora com a proposta da inovação social, visto que a intervenção foi iniciada pelos atores sociais através de uma ação coletiva (Bouchard, 2012). Para a moeda social alcançar o seu propósito, ela deve estar vinculada a uma série de fatores que contribuem para a sua consolidação. A comunidade a ser beneficiada deve ser socialmente e politicamente ativa, lutar pelos seus direitos, ter capacidade de ser organizar coletivamente e entender os princípios e valores da economia solidária, características essas identificadas nos moradores do Conjunto Palmeiras.

Assim, um ponto forte é a participação comunitária para resolver problemas que o bairro enfrenta. Uma das estratégias que os moradores criaram para discutir e buscar soluções de forma conjunta foi através do Fórum Socioeconômico Local e do Conselho do Quarteirão. O Fórum é um espaço de discussão, debate e mobilização comunitária onde os moradores, representantes das entidades do bairro, se reúnem semanalmente para tratar de assuntos pertinentes à comunidade. Já o Conselho do Quarteirão é um espaço associativo entre todos os moradores de um determinado quarteirão. O seu papel é fiscalizar, reivindicar e, principalmente, realizar ações que melhorem a qualidade de vida no quarteirão (Instituto Banco Palmas, 2019). A manutenção é de responsabilidade dos moradores, eles têm o dever de zelar pelo quarteirão e de mantê-lo limpo e organizado, conforme destacou O E3 ao informar que no conjunto já existem 39 conselhos de quarteirão. 
A articulação entre atores sociais nas iniciativas de inovação social pode envolver indivíduos da sociedade civil, cooperativas, associações, sindicatos. Os atores organizacionais são caracterizados como empresas, organizações da economia social, empresas coletivas e beneficiários de organizações privadas. Já os atores institucionais são o Estado e representantes nos níveis federal, estadual e local (Cloutier, 2003; Correia et al., 2016; Tardif \& Harrisson, 2005). No início, o Banco Palmas recebeu auxílio de várias organizações sociais, tais como: a Sociedade Alemã de Apoio Técnico (GTZ), Cáritas local e internacional, entre outras organizações internacionais que visualizaram o potencial do Banco para a região (Melo \& Magalhães, 2007). De acordo com entrevistado E1, a primeira fase do Banco foi marcada por total falta de apoio do Estado, que ficou contra a organização. Portanto, o apoio de atores organizacionais internacionais foram cruciais para o crescimento do Banco e consolidação da moeda social.

No caso do Banco Palmas, há diversas cooperativas que atuam na região gerando emprego e renda. Os trabalhadores podem optar que parte dos seus salários sejam em moeda social eletrônica (e-dinheiro), cujo valor pode ser depositado diretamente pela plataforma digital, sendo aceito nos estabelecimentos e comércios locais.

A Cooperativa Palmafashion é uma marca de roupas da comunidade, em que as peças são confeccionadas pelas mulheres que participam do curso de corte e costura realizados pelo Projeto Elas, que é voltado para capacitação e formação de mulheres para o mercado de trabalho (Braz, 2014). A Cooperativa de trabalho em serviços alimentícios chamada Prato Colorido foi criada com o intuito de disputar outro tipo de consumo que é do Poder Público, ou seja, na prestação de serviços alimentícios para o presídio próximo ao Conjunto Palmeiras. A PalmaCoop é uma Cooperativa Popular de Trabalho em Saneamento Ambiental e envolve as áreas de Gestão de Resíduos Sólidos, Operação e Manutenção de Sistema Abastecimento de Água, de Esgotamento Sanitário e de Drenagem Urbana (Instituto Banco Palmas, 2019). A prefeitura contrata essa Cooperativa para prestar serviços no bairro e assim contribui para a geração de emprego na comunidade.

As associações mais atuantes são a ASMOCONP, que desde 1981 tem prestado assistência aos moradores, articulando movimentos populares e buscando parcerias para estruturar o bairro, e a Associação das Mulheres Emancipadas, que é uma cozinha comunitária que tem como objetivo a geração de trabalho e renda para as mulheres de baixa renda. Com os atores institucionais, o Banco Palmas possui parceria de prestação de serviços, principalmente com prefeituras, conforme ressaltado pelo entrevistado E1:

\footnotetext{
A gente tem parcerias prestação de serviços com prefeituras que é o nosso maior mercado hoje, que a maioria das prefeituras principalmente no Nordeste. Hoje o único projeto que a gente tem de maior é o projeto em parceria com Maricá, eles nos pagam pela assessoria ao projeto da cidade, então a gente faz a assessoria da plataforma digital [...] (Entrevistado E1).
}

A importância das pessoas como protagonistas para criar soluções foi destaque na fala dos entrevistados, em especial quando perguntado sobre o que é inovação social com base na experiência prática vivenciada, conforme pode ser identificado na fala do entrevistado E3: 

infraestrutura. [...] o que gera Inovação social são as pessoas que estão relacionadas dentro desses equipamentos e que são moradoras do bairro e que a cada dia mais vão resistindo, inovando e criando outras coisas (Entrevistado E3).

A articulação entre atores sociais, organizacionais e institucionais somada à cooperação de múltiplos agentes para aplicar o conhecimento, a experiência e a capacidade produtiva dos moradores locais, contribuiu para a geração de soluções que beneficiaram toda a comunidade, corroborando a assertiva de Bignetti (2011) ao tratar dos benefícios das inovações sociais.

A Figura 2 apresenta a síntese dos resultados da dimensão Atores após a verificação empírica. As categorias de análise identificadas foram: Desejo de mudança e iniciativa que está associada à busca de alternativas; Processos participativos e democráticos que estão relacionados à organização comunitária; e, por fim, a Articulação de atores e o processo de cooperação.

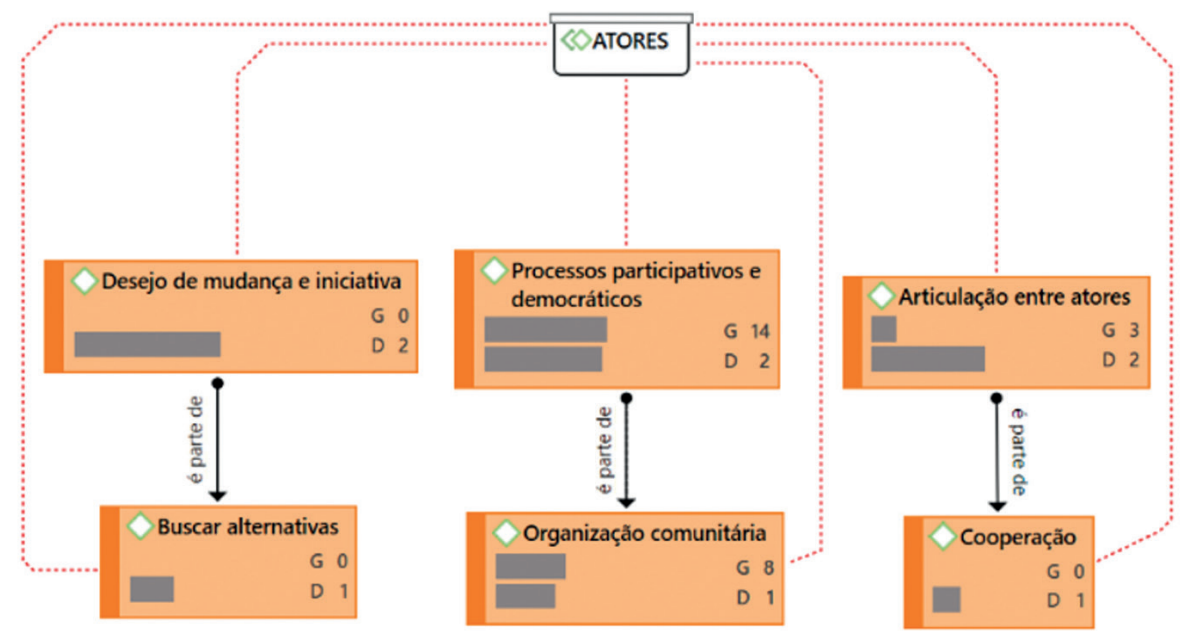

Figura 2. Dimensão Atores

Fonte: Rede gerada no ATLAS.ti, com base nos dados da pesquisa de campo (2019)

Portanto, a necessidade social do contexto dos moradores do Palmeiras fez emergir a iniciativa de inovação social da moeda social operacionalizada pelo Banco Palmas que funciona como um Banco Comunitário de Desenvolvimento. Ao identificar o problema a ser enfrentado, os atores de desenvolvimento local buscaram solucioná-lo por meio de uma organização popular com base na participação comunitária e articulação de atores sociais, cujo objetivo é lidar com os desafios que convivem em suas realidades, dentre os quais se insere o consumo. O propósito é alcançar o desenvolvimento sustentável no território, alavancando a economia local e oferecendo meios complementares de acesso a bens e serviços (Seyfang \& Longhurst, 2013). Isso trouxe ganhos sociais, políticos, econômicos, ambientais para os atores sociais, organizacionais e institucionais envolvidos.

\section{Dimensão inovação}

A inovação social pode gerar mudanças na estrutura social, na forma de interações sociais e práticas alternativas, como também criar novos produtos 
ou uma tecnologia social (Choi \& Majumdar, 2014), denominada no framework como a dimensão "Inovação" e composta pelas seguintes categorias de análise: "novas práticas de produção e consumo"; "estrutura alternativa sustentável"; "coprodução, compartilhamento e tecnologias sociais".

No Banco Palmas, a mudança foi na criação de uma estrutura alternativa sustentável para a geração de trabalho e renda para a população, através de novas práticas de produção e consumo fora do mercado convencional, com o objetivo de criar uma rede local de produtores e consumidores para o desenvolvimento do território, e para que as riquezas geradas permaneçam no local. Ou seja, foram estabelecidas práticas diferenciadas das alternativas tradicionais existentes, de modo a visar melhorias nas condições de vida da coletividade (Correia et al., 2016; Jaeger-Erben et al., 2017; Lorek \& Spangenberg, 2014).

As novas práticas de produção e consumo criadas com o surgimento do Banco Palmas contribuem para fomentar as economias locais, com ações que melhoram a vida das pessoas, distribuindo renda para a população desprovida de recursos, tal como salienta o entrevistado E1: "para nós não é só um serviço, não é só melhorar a vida das pessoas, é criar um outro sistema, provar e praticar, inovar no que é possível em um sistema financeiro, igual, justo, ético, e distributivo".

Para enfrentar a crise, o Banco Palmas está sempre modernizando suas operações, assim como adequando a moeda social às dinâmicas, desafios e especificidades do bairro, mas mantendo a sua essência de ser um banco comunitário para desenvolver a comunidade onde está inserido. Por isso, busca "criar uma capacidade de se organizar coletivamente, buscar soluções coletivas, sair dessas soluções individuais. Pensar outros modelos de consumo [...] consumir menos e melhor. [...] Repensar um novo modelo de consumo" (Entrevistado E1). A gestão do Banco e de suas atividades ressaltam o aspecto interativo e o compartilhamento de conhecimento, recursos e habilidades que contribuem para que os moradores repensem a economia local, passando a assumir um papel mais ativo na busca de modos de produção e consumo alternativos, mediante a prática de coprodução que organiza produtores e consumidores em redes para que a riqueza gerada não saia do bairro.

Considera-se como aspecto relevante a mobilização dos atores locais na captação de recursos que possibilitam enfrentar os seus principais problemas sociais (Klein, Fontan, Harrisson, \& Lévesque 2012). A moeda digital e-dinheiro é caracterizada como uma tecnologia social, por ser uma solução desenvolvida em interação com a comunidade. Essa estratégia foi encontrada de forma a garantir a sustentabilidade do Banco Palmas e a manutenção do seu propósito social, conforme enfatiza os entrevistados E1 e E2:

O Banco Palmas é um projeto social gigante, que tem propriedade coletiva. [...] impacta as pessoas tanto que as pessoas melhoram a qualidade de vida. Não adianta fazer uma tecnologia social em que um vai ficar cada vez mais rico e outro cada vez mais pobre, né?! [...] Para ser tecnologia social, projeto de impacto social, inovação social, tem que ser uma coisa que melhore a vida das pessoas, tem que combater as desigualdades e é propriedade coletiva, senão vira um produto de mercado (Entrevistado E1). 

que hoje é uma saída que a gente tem para realmente fazer um negócio dentro de cada um dos Bancos Comunitários [...] e a gente acredita que dentro do e-dinheiro a gente consiga resolver essa questão da sustentabilidade (Entrevistado E2).

Além da moeda social em si, a ideia de promover um modelo alternativo e repensar o consumo são aspectos destacados por todos os entrevistados, os quais ressaltam o papel da sociedade para alcançar modos de produção e consumo sustentáveis, como evidenciado na fala do entrevistado E1.

\begin{abstract}
Quem tem que tomar a frente do consumo sustentável, sustentabilidade ambiental, sustentabilidade comunitária, é a sociedade consciente disso, é pensando em um modo de desenvolvimento alternativo de viver, de se comportar, de consumir, com novos padrões de consumo, esse é outro debate, complexo [...] Eu acho que não vai ter consumo sustentável se a sociedade não tomar a frente e for protagonista, eu não vou esperar que o mercado faça isso [...] (Entrevistado E1).
\end{abstract}

Considera-se que o banco comunitário e o uso de moeda social enquanto inovação social ajudam na geração de trabalho e renda e mantêm uma relação direta com a questão de acesso ao consumo. A premissa inicial dos fundadores do banco era que bastasse produzir e consumir localmente que o bairro se desenvolveria por meio de uma rede local de produtores e consumidores. Todavia, com a crise e o desemprego, alternativas foram repensadas para atender a uma nova dinâmica e aproveitar uma oportunidade de gerar trabalho e renda para a comunidade. Assim, a alternativa foi disputar o consumo do poder público através de cooperativas que possibilitam atuar como fornecedores, tal como é evidenciado pelo Entrevistado E1: "Estamos hoje já muito perto de fechar um contrato com a prefeitura para toda a limpeza do bairro pra gente fazer e também vender alimentos [...]".

Busca-se sempre incentivar aformação de uma rede local de produtores e consumidores que seja valorizada pelos moradores. Inicialmente foi feito uma pesquisa sobre o mapa do consumo do bairro para saber o quê e onde os moradores compravam os itens para suprir suas necessidades básicas. Os resultados da pesquisa mostraram que o montante de $R \$ 1.540 .251,88$ (um milhão e quinhentos e quarenta mil, duzentos e cinquenta e um reais e oitenta e oito centavos) eram gastos mensalmente pelas famílias do Conjunto Palmeiras. Porém, os moradores não compravam no próprio bairro, por isso perdiam suas poupanças internas, pois as riquezas geradas iam para outros territórios (Melo \& Magalhães, 2007).

A criação da rede local de produtores e consumidores impulsionou o desenvolvimento da comunidade, incentivando os moradores a comprar e vender no próprio bairro. De acordo com o Entrevistado E1, "toda lógica do Banco Palmas é o que a gente chama de "prosumatores", nós somos produtores e consumidores ao mesmo tempo e atores sociais de transformação". Portanto, os moradores atualmente encontram tudo o que precisam dentro do próprio bairro.

O bairro possui espaços de comercialização solidária, tais como Bodega Solidária, a Feira Solidária e o Bodegão da Solidariedade que comercializam artesanatos e confecções produzidas pelas associações das mulheres, entre outros produtos locais que são expostos e vendidos tanto em real quanto em e-dinheiro. Sendo assim, a comunidade empenhou-se 
em criar alternativas para enfrentar o desemprego por meio de cooperativas que aproveitam as potencialidades locais dos moradores e de sua capacidade produtiva. A moeda social auxilia nesse processo por gerar inclusão financeira, fazendo uso dos recursos endógenos e incrementando a economia local. Assim, as soluções e alternativas criadas relacionadas às questões de consumo abrangeram atividade econômica democrática, participativa, integrando valores, preocupações e necessidades sociais para o desenvolvimento de localidades (Briceno \& Stagl, 2006).

Mediante os resultados alcançados no caso investigado, a dimensão Inovação está associada a uma estrutura alternativa sustentável com suas respectivas categorias e subcategorias de análise, conforme expostos na Figura 3.

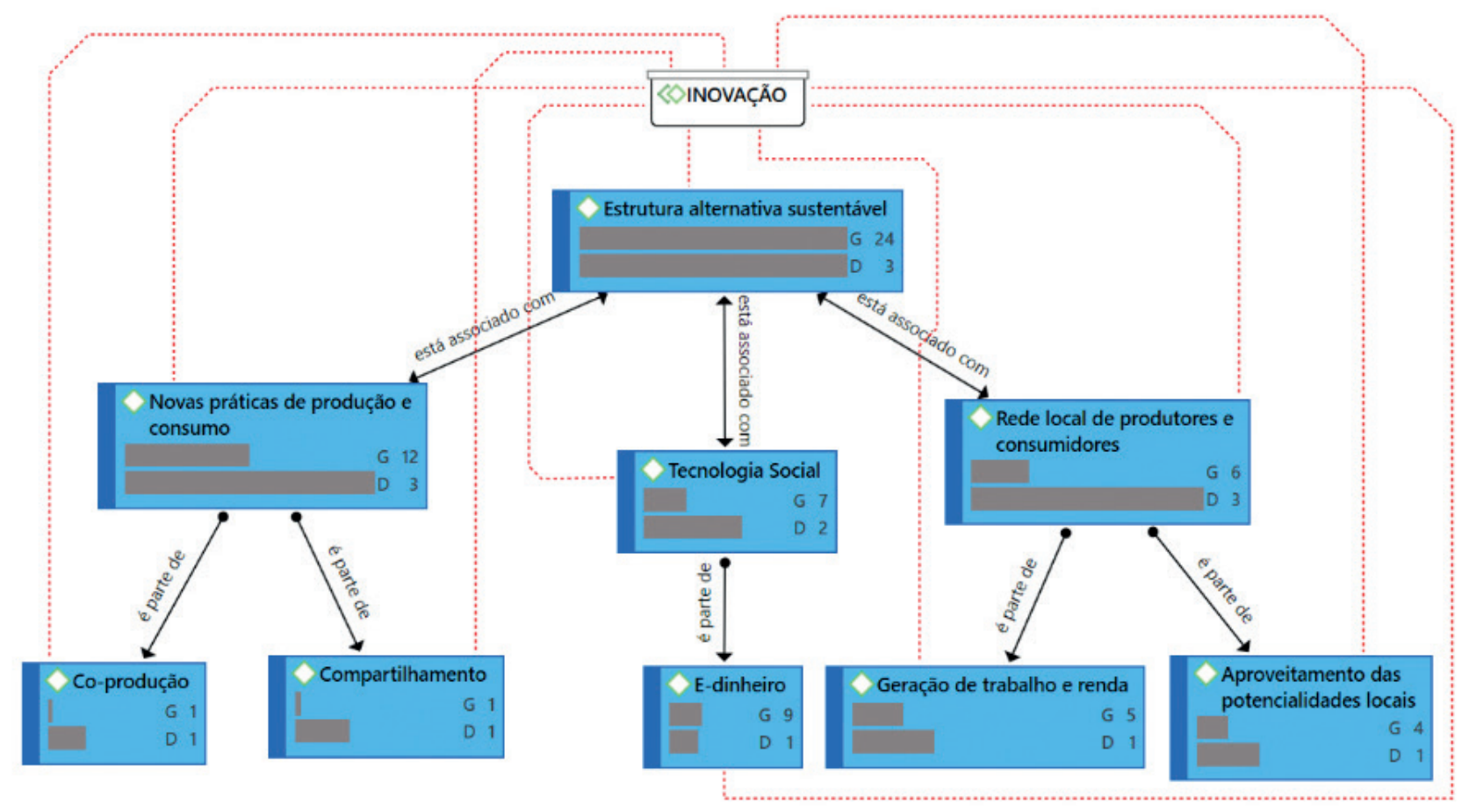

Figura 3. Dimensão Inovação

Fonte: Rede gerada no ATLAS.ti, com base nos dados da pesquisa de campo (2019)

A inovação ocorre a partir da adoção de uma estrutura alternativa sustentável com base nas novas práticas de produção e consumo, coprodução, compartilhamento e tecnologia social, que no caso estudado é a moeda social eletrônica (e-dinheiro); formando uma rede local de produtores e consumidores para a geração de trabalho e renda, aproveitando as potencialidades locais do Conjunto Palmeiras que têm potencial de contribuição para a promoção do consumo sustentável na região.

\section{Dimensão mudança cultural e social}

A dimensão "Mudança cultural e social" considera que as decisões e ações dos consumidores são partes de práticas não só culturais, mas também sociais, que estão inseridas em rotinas diárias e estruturas pré-estabelecidas difíceis de serem alteradas. As categorias de análise elencadas 
no framework foram: "estilo de vida mais sustentáveis"; "novas relações sociais"; "valorização da produção e do consumo local"; e "aproveitamento das potencialidades do contexto". A abordagem do consumo da inovação social representa um novo caminho para uma população atender a uma categoria de necessidades, seja na área de alimentação, transporte, saúde, entretenimento etc., as quais envolvem mudanças nos hábitos de consumo de uma sociedade para garantir o seu bem-estar social (Cloutier, 2003).

O estilo de vida determina os hábitos e comportamento no que diz respeito ao consumo de recursos e na geração de resíduos no meio ambiente, porém a dificuldade é provocar mudanças nos modos de pensar e agir da sociedade (Figueroa-Garcia, Garcia-Machado, \& Perez-Bustamante Yabar, 2018). As mudanças identificadas para estilos de vida sustentáveis nos moradores foram uma maior conscientização para evitar o desperdício de materiais, aproveitamento de alimentos, uso de composteiras para alimentos orgânicos e reciclagem (Geiger, Fischer, \& Schrader, 2018), que são práticas que contribuem para a sustentabilidade do consumo. Os entrevistados relataram algumas práticas que a comunidade realiza, como pode ser observado no seguinte trecho.

Aqui a gente trabalha com a questão da alimentação saudável, da horta, da compostagem. As composteiras estão no quarteirão que são para os moradores também, eles vão lá e colocam casca de verdura, pó de café. [...] Então mudou muito essa conscientização das pessoas, e até o pó de café, a palha do gogó que era jogada fora hoje não é mais, e que ela pode fazer uma compostagem na casa dela, ter o seu próprio adubo orgânico [...] (Entrevistado E3).

As transformações nas estruturas e práticas sociais que as inovações sociais potencializam (Choi \& Majumdar, 2014) contribuem para a construção de novas relações sociais com base na confiança, participação, solidariedade (Bouchard, 2012; Howaldt \& Schwarz, 2016; Rollin \& Vincent, 2007). A confiança foi destacada no processo implantado pelo Banco Palmas, conforme enfatiza o E2.

a gente conseguiu uma história de muita confiabilidade, então tem muito dessa relação da confiança [...] a gente criou uma confiabilidade muito grande com comunidade que facilita esse processo, mas foi realmente muito difícil no início [...] trabalhar com recursos de forma humanizada, aí ninguém acredita né?, porque como você trabalha com dinheiro sem selvageria?! (Entrevistado E2).

A valorização da produção e consumo local foi conquistada gradativamente através do incentivo do Banco Palmas. Foram feitas campanhas para mostrar a importância de comprar de empreendimentos locais para desenvolver o bairro. Os entrevistados enfatizaram essa cultura da valorização da produção e do consumo local, que favorece o desenvolvimento da comunidade.

É o bairro que aprendeu a gostar do local [...] tem muito mais gente que consome aqui, muito mais grupos que surgem com o nome daqui [...] essa pegada do Banco de criar a moeda local, criar um dinheiro local terminou impactando numa cultura de valorização do local, aí serve para tudo, serve para consumir produtos como também pensar nas formas de organização, de participação, de envolvimento da comunidade. Então hoje é uma comunidade que pensa, se valoriza se orgulha muito mais de si[...] (Entrevistado E1). 
Alguns fatores que facilitaram o desenvolvimento da moeda social no Banco Palmas, enquanto mudança cultural e social, foram a gestão participativa, rede de colaboração, organização comunitária, engajamento dos atores envolvidos, relações com base na confiança e aprendizagem coletiva, o que corroboram com os aspectos apontados por Bataglin (2017). A Figura 4 apresenta a dimensão mudança cultural e social que foram levantadas na pesquisa, com as seguintes categorias de análise: estilo de vida mais sustentáveis; conscientização; novas relações sociais; confiança e valorização da produção e do consumo local.

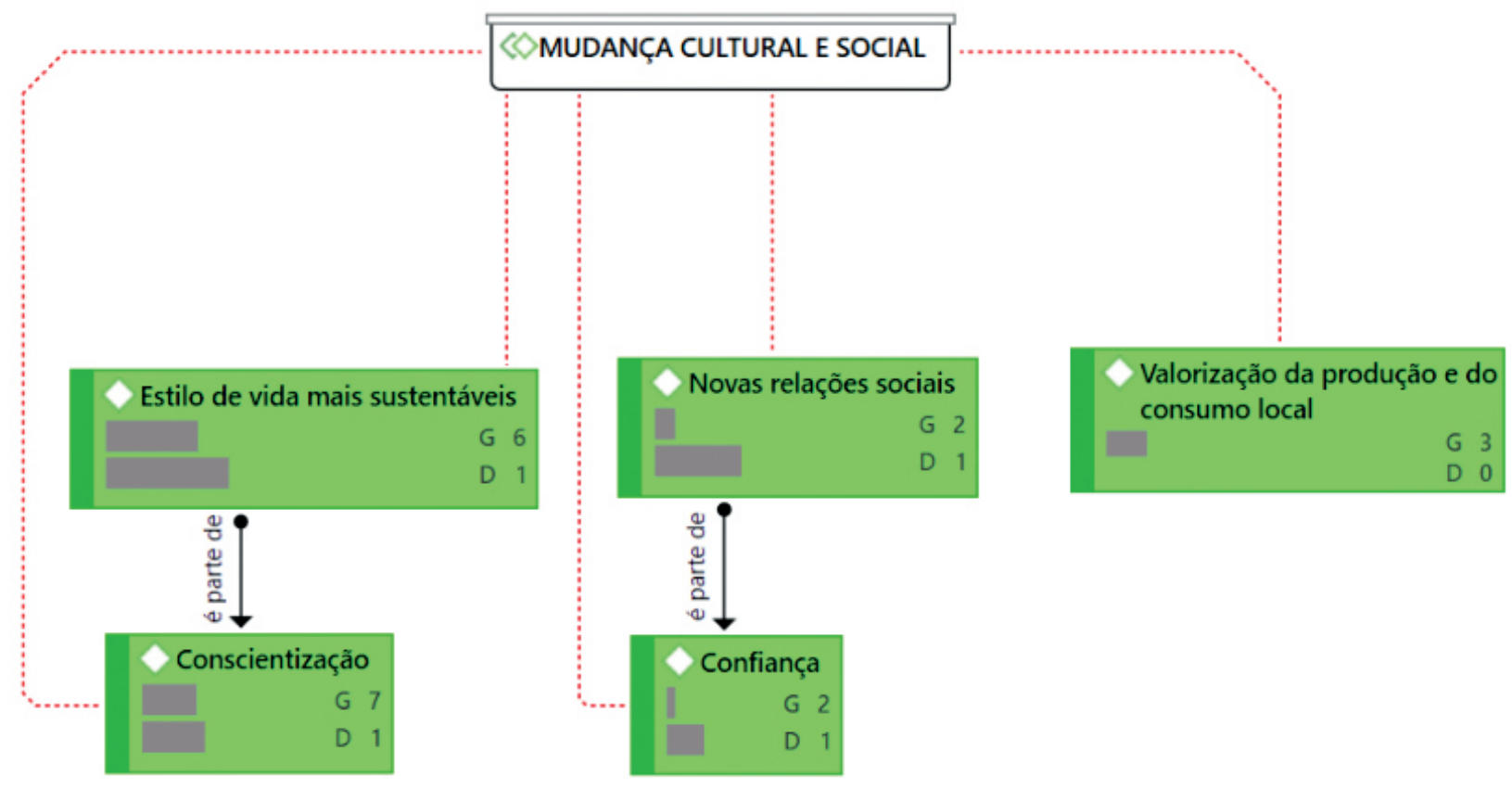

Figura 4. Dimensão Mudança cultural e social

Fonte: Rede gerada no ATLAS.ti, com base nos dados da pesquisa de campo (2019)

A mudança cultural e social para estilos de vida mais sustentáveis ocorre a partir de uma maior conscientização, com novas relações sociais com base na confiança, cooperação, solidariedade (Howaldt \& Schwarz, 2016; Rollin \& Vincent, 2007) e valorização da produção e do consumo local. Tais elementos são cruciais para o consumo sustentável, pois os envolvidos compartilham um conjunto de valores relacionados à sustentabilidade, equidade e descentralização, com o objetivo de adotar estilos de vida alternativos e novas formas de organização social (Jaeger-Erben et al., 2017) que impactam diretamente em suas práticas cotidianas de consumo.

\section{Dimensão transformação social}

A dimensão "Transformação social" é colocada como resultado da inovação social, por meio das mudanças nas estruturas e práticas sociais que as inovações sociais induzem nas rotinas e estruturas estabelecidas (Choi \& Majumdar, 2014). As categorias de análise são: "emancipação e empoderamento"; "participação cívica"; "melhores condições de vida"; "inclusão social, equidade e bem-estar coletivo"; "difusão e replicabilidade". 
A inovação social com foco no indivíduo refere-se a um processo de aprendizagem, empoderamento e autonomia dos participantes para a resolução de problemas, de forma a responder às necessidades ou uma aspiração (Cloutier, 2003). O Banco Palmas sensibiliza a comunidade para se empoderar e ser protagonista, tendo em vista que foi ela que construiu a estrutura em que o bairro se encontra atualmente.

Para um dos entrevistados, a emancipação e o empoderamento são facilitados através da criação de "ambientes favoráveis para a inovação [...] é dar espaços de convivência, relacionamentos, colocar a comunidade para pensar, empoderar as pessoas. Criar nas pessoas o sentimento que elas podem, elas têm poder, elas são capazes". (Entrevistado E1). O Banco contribui nesse aspecto, dando autonomia e liberdade aos participantes, visto que "O papel de um banco comunitário não é só a parte financeira. O trabalho e a renda é o foco, é a meta, mas é organizar as pessoas, empoderar as pessoas, as pessoas se sentirem mais felizes, mais organizadas"1

Mas a gente sensibiliza de que eles são protagonistas, que eles são donos do bairro, e que só acontece as coisas aqui quando a gente quer [...] (Entrevistado E3).

As experiências e iniciativas da Economia Solidária (ES), tal como ocorre no Banco Palmas, buscam soluções com base na emancipação dos indivíduos, o que corrobora a definição de Borinelli, Santos e Pitaguari (2010, p. 2).

Emancipar-se é entendido então por atingir a maioridade de consciência, com autonomia de conhecimento e de percepção da realidade [...] A emancipação perseguida pelas experiências de ES apresenta-se economicamente por meio de organizações de autogestão, buscandose construir modelos inovadores de produção e de sociabilidade amparados em fortes princípios de participação e de cooperação [...]

O entrevistado E1 ressaltou a contribuição do Banco Palmas para emancipação por meio da capacitação dos moradores que buscam algum curso visando qualificação, assim como serem multiplicadores de conhecimento para outras pessoas terem também a oportunidade de crescer pessoalmente e profissionalmente. Nesse sentido, o microcrédito é fundamental, mas "só tem sentido se for acompanhado por uma série de fatores: os pequenos negócios têm que ser acompanhados com estratégias de desenvolvimento local, territorial, com estímulo a comercialização, capacitação do produtor"'.

O Banco Palmas oferece vários projetos que visam a formação dos moradores, tais como: educação financeira, culinária, corte e costura, programação e inúmeros outros. O Projeto Elas, por exemplo, promove ações para a formação e orientação às mulheres do programa do Bolsa Família, que já obtiveram crédito no Banco. O projeto promove capacitação profissional para o mercado de trabalho, visando a inclusão sócio produtiva, financeira e bancária das mulheres beneficiárias (Braz, 2014).

1 Depoimento de Joaquim de Melo, 2010. Recuperado em 19 agosto, 2019, de https://www.youtube. com/watch?v=C9nk8HpFjAE

2 Depoimento de Joaquim de Melo, 2010. Recuperado em 19 agosto, 2019, de https://www.youtube. $\mathrm{com} /$ watch?v=TDCUtOchu1U 
São três princípios que a gente tem inalienáveis, que é a identidade [...] autonomia [...] e essa capacidade de formação, do processo formativo, de curta, média e longa duração importantíssimo. [...] Então o processo formativo da comunidade, a formação presencial, de sala de aula, de curso, treinamento, ou essa formação do dia a dia, que vem pela arte, pela cultura, pelas reuniões. Toda reunião é um processo formativo [...] você não forma um líder comunitário, um líder social numa sala de aula, ele tem que ter a vontade de querer ser, mas a instituição facilita processos, cria programas, projetos para isso (Entrevistado E1).

Todos esses projetos de capacitação geram inclusão social, como o Bairro Escola de Trabalho, por exemplo, que tem como objetivo oferecer aos jovens uma oportunidade de trabalho, ganhando experiência com os próprios comerciantes locais. Como incentivo, os jovens recebem uma bolsa e participam de capacitações e formação profissional (Braz, 2014). Há também a incubadora feminina, que auxilia as mulheres em situações de risco, com o objetivo de integrá-las à rede de produtores e consumidores do bairro (Melo \& Magalhães, 2007).

Para o desenvolvimento de soluções tecnológicas, existe no bairro o Palmatech que é um laboratório de Inovação e Pesquisa. A finalidade é desenvolver soluções e produtos que potencializem as atividades desenvolvidas pelos bancos comunitários, através do uso da Tecnologia da Informação (TI). O laboratório também promove a capacitação de jovens da comunidade (Braz, 2014). Todas essas capacitações e formações transformaram a vida dos moradores através dos projetos e ações que o banco realiza.

Assim, o Banco Palmas e a moeda social proporcionaram melhores condições de vida no que diz respeito a oportunidades de trabalho e acesso ao consumo para a satisfação das necessidades básicas, por meio da capacitação e formação profissional. Antes do Banco, os moradores teriam que se deslocar para outros bairros para comprar itens básicos de consumo, pagar contas, entre outros assuntos necessários para resolver em seu cotidiano. Além dessas melhorias, a moeda social possibilitou a inclusão financeira por meio de um sistema adaptativo e inclusivo à realidade local, por possibilitar acesso ao crédito que não é concedido pelos bancos convencionais, seja por restrições financeiras ou pela ausência de bancos em regiões marginalizadas, tal como reforça o sujeito E1 "o Banco comunitário não quer competir com o banco tradicional. O problema é que o banco tradicional não chega a comunidades ribeirinhas, quilombolas, assentamentos..."

Tudo tem no bairro. Antigamente no começo do bairro (ele já vai fazer 46 anos), só existiam aquelas "bodeguinhas", não tinha tudo o que a gente necessitava né?! Aí tipo, se você tivesse o dinheiro para fazer compras de um mês, na "bodega" não tinha o suficiente, aí a gente tinha que se deslocar para o bairro mais próximo e desenvolvido, ou então você tinha que ir para o centro mesmo da cidade. [...] Tudo o que você queria resolver, tipo pagar uma conta, tinha o Banco Palmas, no Palmeiras. Se não tivesse o Banco eu tinha que ir para outro bairro [...] (Entrevistado E4).

Outro aspecto positivo foi a segurança no bairro além da diminuição das desigualdades devido às oportunidades concedidas e dos incentivos oferecidos, tal como foi destacado pelo entrevistado E2.

\footnotetext{
A gente vive hoje um momento de pacificação bem legal, já teve momentos muito complicados, ambientes hostis, mas estamos num ambiente muito tranquilo [...] o Conjunto Palmeiras em essência a gente diminui o nível de criminalidade, aumentou a renda, conseguiu estabilizar de relações [...] acho que essa consciência do local. Tipo assim: eu não moro mais no lugar mais violento do mundo (Entrevistado E2).
} 
A experiência exitosa do Banco Palmas e da sua moeda social possibilitou geração de riqueza local a partir das operações realizadas na plataforma digital, as quais contribuíram para a abertura de diversos empreendimentos devido às diferentes modalidades de acesso ao crédito oferecidas. Ressalta-se que a maioria dos moradores possuíam restrições em outras modalidades disponíveis para conseguir recursos, o que impossibilitava a sustentabilidade dos pequenos negócios.

\begin{abstract}
O Banco tem resultados bem concretos. Recentemente a Universidade Federal do Ceará, a pedido do ministério do trabalho fez um estudo, e tem número bastante interessante: $90 \%$ das pessoas entrevistadas afirmaram que o Banco Palmas melhorou sua qualidade de vida; $25 \%$ conseguiu emprego; 23\% montou seu próprio negócio; 20\% conheceu outras pessoas, criou redes de relacionamentos e essas redes fizeram com que conseguisse trabalho, melhorasse sua vida ou tivesse sua moradia; 98\% reconhecem que o desenvolvimento do Palmeiras veio depois do Banco Palmas [...] Então temos resultados econômicos bem concretos $[\ldots]^{3}$
\end{abstract}

No que diz respeito a difusão e replicabilidade, a iniciativa se difundiu localmente, sendo replicada em mais 100 municípios brasileiros (Rigo \& França, 2017). Como exemplo, tem-se o caso da moeda "Mumbuca" que foi a primeira moeda social eletrônica do Brasil, criada em 2013 pelo Banco Comunitário de Maricá no Rio de Janeiro, e foi projetada para atender uma política pública da Prefeitura da cidade, integrada ao auxílio de uma bolsa para famílias de baixa renda que receberam o pagamento por meio da moeda social eletrônica (Oliveira, 2019).

A Figura 5 apresenta os resultados da dimensão Transformação Social no caso investigado com as seguintes categorias de análise: emancipação e empoderamento; capacitação; formação; inclusão social; melhores condições de vida; oportunidades de trabalho; acesso ao crédito; bem-estar coletivo; diminuição das desigualdades; segurança; difusão e replicabilidade.

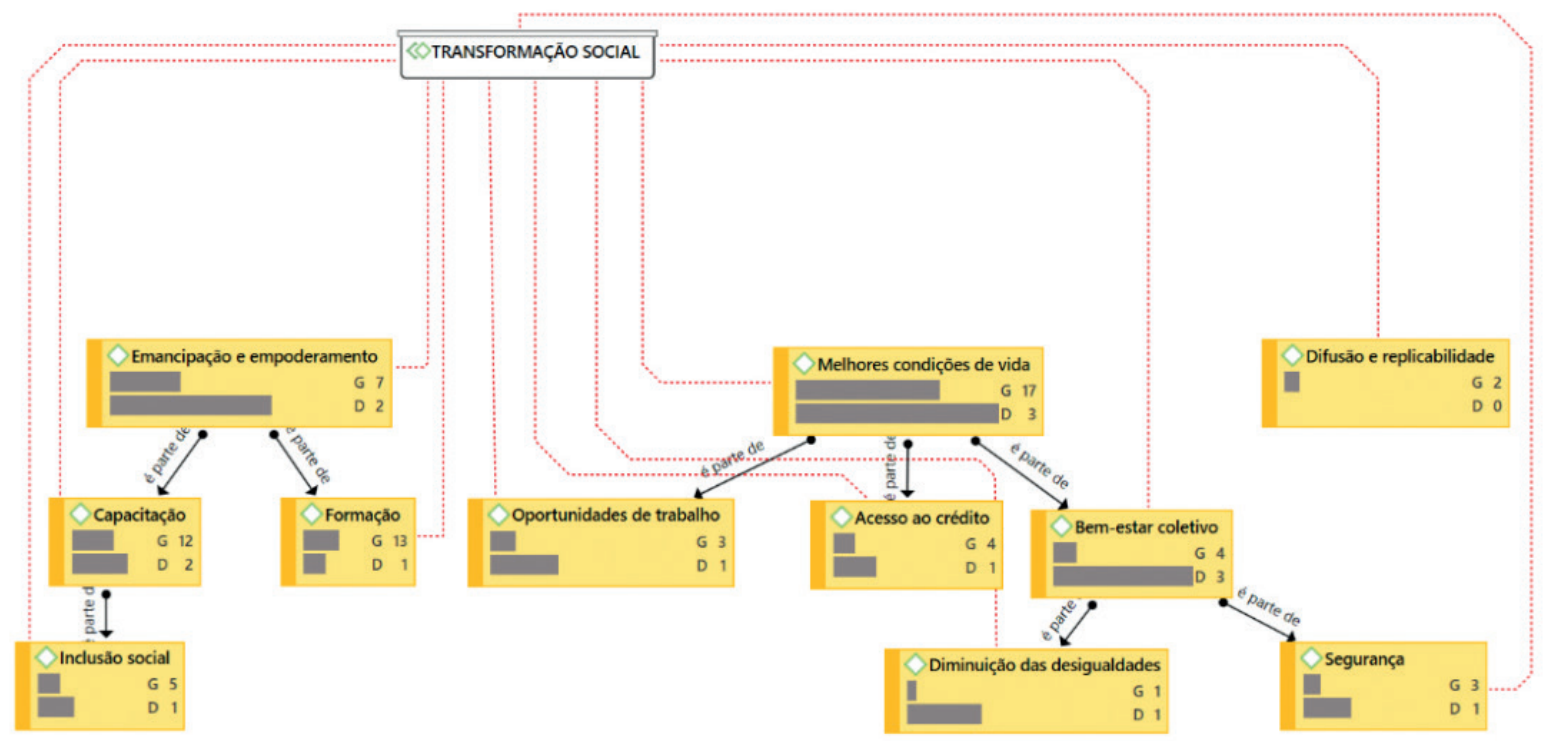

Figura 5. Dimensão Transformação Social

Fonte: Rede gerada no ATLAS.ti, com base nos dados da pesquisa de campo (2019)

3 Depoimento de Joaquim de Melo, 2010. Recuperado em 19 agosto, 2019, de https://www.youtube. $\mathrm{com} /$ watch?v=C9nk8HpFjAE 
Portanto, como evidenciado nas falas dos entrevistados, o Banco Palmas trouxe inúmeros benefícios para a comunidade, no âmbito social, econômico, pessoal e político, transformado realidades e perspectivas de vida. Quando perguntando sobre o significado da inovação social, um dos entrevistados ressaltou as seguintes características:

\begin{abstract}
A inovação tem que ter uma meta que é enfrentar as desigualdades. Eu acho que inovação social é uma forma diferente de fazer as coisas, pode ser na forma de tecnologia ou não. [...] Novas formas de você reconstruir a vida, refazer as coisas, de pensar as coisas, com um princípio, com um propósito, que é enfrentar a pobreza, enfrentar a desigualdade, buscar o bem-viver das pessoas [...] é uma nova forma de se fazer que melhora a vida das pessoas [...] (Entrevistado E1).
\end{abstract}

A resposta do entrevistado está de acordo com conceito de inovação social que envolve o atendimento das necessidades sociais, a promoção da inclusão social, desenvolvimento e capacitação dos indivíduos (André \& Abreu, 2006; Bouchard, 2012; Mulgan et al., 2007) que buscam melhores condições de vida. Assim, o caso empírico de inovação social estudado apresentou elementos que podem contribuir com o tripé da sustentabilidade, quando associado ao consumo em diversos aspectos. Na dimensão social, promove ações e projetos que geram inclusão social, educação, desenvolvimento, saúde, proteção, segurança e satisfação de necessidades. Na dimensão ambiental, protege o meio ambiente através do uso responsável dos recursos naturais, reduzindo os impactos ambientais e considerando as fases de aquisição, uso e o descarte de produtos. E na dimensão econômica tem-se a geração de emprego e renda, melhorando, assim, o capital social e humano, e fomentando as economias locais (Geiger et al., 2018; Hansmann, Mieg, \& Frischknecht, 2012).

Portanto, os resultados deste estudo demonstraram a importância dos elementos que relacionam a inovação social a um meio de promoção do consumo sustentável, ampliando a compreensão da capacidade de agir da sociedade, não só em suas ações e comportamentos individuais enquanto consumidores, mas também em torná-los membros ativos de um processo de mudança social ao contribuir para questões relacionadas à sustentabilidade, como verificado no caso do Banco Palmas e sua moeda social. As evidências teóricas e empíricas apontam para a contribuição das iniciativas de inovação social em promover estruturas sustentáveis que ancorem as práticas de consumo fora do mercado convencional.

\title{
Conclusão
}

O objetivo deste artigo foi analisar os elementos de inovação social que podem contribuir para promoção do consumo sustentável. Para tanto, foi realizado um estudo de caso da moeda social operacionalizada pelo Banco Palmas e o framework proposto por Araújo (2020). Com a verificação empírica das dimensões do framework que apresenta os elementos que relacionam as duas temáticas no caso investigado, constatou-se que iniciativas advindas dos próprios consumidores que se organizam para buscar alternativas decorrentes das inovações sociais, no intuito de suprir suas necessidades básicas, são promissoras para impulsionar o consumo sustentável, 
considerando o enfoque atribuído às questões sociais, ambientais e econômicas do processo. Além disso, foram constatados avanços no acesso ao consumo e nos padrões, com estímulo ao desenvolvimento de uma rede local de produtores e consumidores, além da promoção de melhorias nas condições de vida da comunidade.

O diferencial dos moradores do Conjunto Palmeiras é sua vitalidade comunitária e resiliência diante dos desafios sociais vividos. Uma população que outrora foi marginalizada reuniu esforços coletivos e com muita luta e perseverança buscou meios de sobrevivência perante o cenário precário ao qual foram submetidos. O Banco Palmas e a moeda social desempenharam um papel-chave nesse processo, porque reorganizaram a economia local ao evitar que as riquezas geradas fossem transferidas para outros territórios, incentivando a valorização dos recursos e potencialidades locais para que a autonomia financeira fosse adquirida.

Para que a região se desenvolvesse, criou-se um sistema econômico no bairro, de forma a oferecer incentivos para o consumo local com a moeda social, a comercialização solidária e a formação de uma rede de produtores e consumidores, assim, as riquezas geradas permaneciam na comunidade. Dessa forma, uma estrutura alternativa de produção e consumo foi criada, através da moeda social, com novas formas de organização popular e com serviços para suprir diversas necessidades sociais do bairro, incluindo as de consumo.

A capacidade de organização popular, a iniciativa de participação e a articulação de atores sociais diversos buscando constantes melhorias no local foram determinantes na construção do bairro. Isso reforça o princípio da inovação social de que a sociedade é capaz de encontrar soluções para suas próprias necessidades sociais. Diante da situação de vulnerabilidade e exclusão social em que os moradores viviam, eles se articularam por meio de um processo coletivo para encontrar meios de promover o desenvolvimento da comunidade. O Banco Comunitário atrelado à circulação de uma moeda social eletrônica criada como alternativa de combate à pobreza foram essenciais no processo de transformação social ocorrido no Conjunto Palmeiras, onde o Banco Palmas está localizado.

Vale ressaltar que foram criados espaços de incentivo para a autonomia, valorização do indivíduo e empoderamento na busca pela emancipação dos atores sociais da comunidade. Assim, considera-se que os impactos gerados pelo Banco Palmas extrapolam o aspecto financeiro que é a concessão de crédito aos moradores por meio da moeda social. Em decorrência dessa inovação social, outros benefícios têm sido gerados para a comunidade, como a criação de emprego e geração de renda, fortalecimento da cultura local e dos laços de confiança, solidariedade, capacitações, crescimento comercial e social da região, o que favorece uma estrutura de produção e consumo sustentável, conforme apontado na literatura.

Diante da complexidade sobre o assunto, recomenda-se uma pesquisa que submerja a outros níveis de extração, com a possibilidade de realizar o estudo de casos e comparações. Apesar disso, este estudo mostra-se relevante por explorar as contribuições que as inovações sociais do tipo moeda social, operacionalizadas por um banco comunitário, trazem para a 
resolução de problemas sociais, promovendo ganhos transversais para a comunidade onde está inserido, inclusive em relação ao acesso ao consumo, principalmente para populações de baixa renda.

O investimento em políticas socioeconômicas e o incentivo do governo em iniciativas como o Banco Palmas e as moedas sociais poderiam ampliar as ações das organizações sociais que se propõem a transformar territórios com base em soluções inovadoras, inclusivas e sustentáveis. A experiência analisada neste estudo pode contribuir na formulação de políticas públicas que possam ajudar a potencializar a difusão em outras regiões e comunidades. Porém, deve-se enfatizar que é um desafio complexo, pois engloba uma série de fatores e demanda a ação de múltiplas partes interessadas, como um esforço coletivo necessário para garantir a sobrevivência das gerações atuais e futuras conforme previsto na Agenda 2030.

Destarte, a compreensão da inovação social a partir da perspectiva do consumo sustentável ressalta a importância de analisar os novos formatos organizacionais de produção e consumo que estão surgindo na sociedade, com soluções inovadoras e inclusivas para atender às necessidades sociais e promover estruturas sustentáveis. Como sugestão de pesquisas futuras, sugere-se que o framework seja verificado em outras iniciativas de inovação social para identificar quais outros elementos são importantes para a promoção do consumo sustentável no contexto brasileiro.

\section{Agradecimento}

O presente trabalho foi realizado com apoio da Coordenação de Aperfeiçoamento de Pessoal de Nível Superior Brasil (CAPES - Código de Financiamento 001) e do Conselho Nacional de Desenvolvimento Científico e Tecnológico (CNPQ). Agradecemos às contribuições dos revisores que, com suas recomendações e sugestões, contribuíram para o aprimoramento do artigo.

\section{Referências}

Abdulrazak, S., \& Quoquab, F. (2018). Exploring consumers' motivations for sustainable consumption: a self-deterministic approach. Journal of International Consumer Marketing, 30(1), 14-28. https://doi.org/10.1080/08961530.2017.1354 350

Agostini, M. R., Vieira, L., \& Bossle, M. B. (2016). Social innovation as a process to overcome institutional voids: a multidimensional overview. RAM. Revista de Administração Mackenzie, 17(6), 72-101. https://doi.org/10.1590/1678-69712016/ administracao.v17n6p72-101

Amorim, D. F., \& del Río, J. (2019). As contribuições e as correlações de dois modelos teóricos para o conceito de sócio sustentabilidade urbana: Rio (2015) e Rio e Amorim (2017). Project Design and Management, 1(2), 25-40. https://doi.org/ https://doi.org/10.29314/pdm.v1i2.162 
André, I., \& Abreu, A. (2006). Dimensões e espaços da inovação social. Finisterra, 41(81), 121-141. https://doi.org/10.18055/Finis1465

Araújo, A. C. M. (2020). Consumo sustentável e inovação social: explorando relações teóricas e empíricas. Dissertação de Mestrado, Universidade Federal de Campina Grande, Campina Grande, PB, Brasil.

Atrek, B., \& Ílter, B. (2017). Social innovation practices in services for sustainable consumption. The Case of Turkey. In Promotional Strategies and New Service Opportunities in Emerging Economies (Cap. 2, pp. 32-65). IGI Global. doi: 10.4018/978-1-5225-2206-5.ch002

Banco Palmas (2010). Banco Palmas: 100 perguntas mais frequentes. Recuperado em 15 setembro, 2019, de http://es.slideshare.net/bancopalmas/banco-palmas100-perguntas-mais-frequentes.

Bardin, L. (2011). Análise de conteúdo. São Paulo: Edições 70.

Bataglin, J. C. (2017). Barreiras e facilitadores da inovação social: estudo de casos múltiplos no Brasil. Tese de doutorado, Universidade de São Paulo, São Paulo, SP, Brasil.

Bengtsson, M., Alfredsson, E., Cohen, M., Lorek, S., \& Schroeder, P. (2018). Transforming systems of consumption and production for achieving the sustainable development goals: moving beyond efficiency. Sustainability Science, 13(6), 1533-1547. https://doi.org/10.1007/s11625-018-0582-1

BEPA. (2010). Empowering people, driving change: social innovation in the European Union. Publications Office of the European Union.

Bignetti, L. P. (2011). As inovações sociais: uma incursão por ideias, tendências e focos de pesquisa. Ciências Sociais Unisinos, 47(1), 3-14.

Borinelli, B., Santos, L. M. L. D., \& Pitaguari, S. O. (2010). Socioeconomia solidária: propostas e perspectivas. Economia Solidária em Londrina: aspectos conceituais e a experiência institucional, Londrina: Universidade Estadual de Londrina.

Bouchard, M. J. (2012). Social innovation, an analytical grid for understanding the social economy: the example of the Quebec housing sector. Service Business, 6(1), 47-59. https://doi.org/10.1007/s11628-011-0123-9

Braz, J. O. B. (2014). Os dilemas de se estar no fio da navalha: a experiência do Banco Palmas e suas práticas cotidianas. Tese de doutorado, Universidade de São Paulo, São Paulo, SP, Brasil.

Briceno, T., \& Stagl, S. (2006). The role of social processes for sustainable consumption. Journal of Cleaner Production, 14(17), 1541-1551. https://doi. org/10.1016/j.jclepro.2006.01.027

Caulier-Grice, J., Davies, A., Patrick, R., \& Norman, W. (2012). Defining social innovation. (Research Report №. 290771) Recuperado em 15 setembro, 2019, de https://youngfoundation.org/wpcontent/uploads/2012/12/TEPSIE.D1.1.Report. DefiningSociallnnovation.Part-1-defining-social-innovation.pdf.

Choi, N., \& Majumdar, S. (2014). Social entrepreneurship as an essentially contested concept: opening a new avenue for systematic future research. Journal of Business Venturing, 29(3), 363-376. https://doi.org/10.1016/j.jbusvent.2013.05.001 
Cloutier, J. (2003). Qu'est-ce que l'innovation sociale? Études théoriques et méthodologiques. Centre de recherche sur les innovations Sociales. Crises Montréal. Recuperado em 15 setembro, 2019, de https://crises.uqam.ca/cahiers/et0314quest-ce-que-linnovation-sociale/

Colglazier, W. (2015). Sustainable development agenda: 2030. Science, 349(6252), 1048-1050.

Correia, S. É. N., Oliveira, V. M. D., \& Gomez, C. R. P. (2016). Dimensions of social innovation and the roles of organizational actor: the proposition of a framework. RAM. Revista de Administração Mackenzie, 17(6), 102-133.

Costa, D. V., \& Teodósio, A. S. S. (2011). Desenvolvimento sustentável, consumo e cidadania: um estudo sobre a (des)articulação da comunicação de organizações da sociedade civil, do estado e das empresas. RAM. Revista de Administração Mackenzie, 12(3), 114-145 https://doi.org/10.1590/S1678-69712011000300006

Creswell, J. W. (2010). Projeto de pesquisa métodos qualitativo, quantitativo e misto. Porto Alegre: Artmed.

Deserti, A., \& Rizzo, F. (2019). Context dependency of social innovation: in search of new sustainability models. European Planning Studies, 28(5), 864-880. https://doi.or g/10.1080/09654313.2019.1634005

Di Giulio, A., Schweizer, C. R., Defila, R., Hirsch, P., \& Burkhardt-Holm, P. (2019). "These grandmas drove me mad. It was brilliant!" Promising starting points to support citizen competence for sustainable consumption in adults. Sustainability, 11(3), 681. https://doi.org/10.3390/su11030681

Domanski, D., Howaldt, J., \& Kaletka, C. (2019). A comprehensive concept of social innovation and its implications for the local context: on the growing importance of social innovation ecosystems and infrastructures. European Planning Studies, 28(3), 454-474. https://doi.org/10.1080/09654313.2019.1639397

Figueroa-Garcia, E. C., Garcia-Machado, J. J., \& Perez-Bustamante Yabar, D. C. (2018). Modeling the social factors that determine sustainable consumption behavior in the community of madrid. Sustainability, 10(8), 1-16. https://doi.org/10.3390/ su10082811

Fuchs, D. A., \& Lorek, S. (2005). Sustainable consumption governance: a history of promises and failures. Journal of Consumer Policy, 28(3), 261-288.

Geiger, S. M., Fischer, D., \& Schrader, U. (2018). Measuring what matters in sustainable consumption: an integrative framework for the selection of relevant behaviors. Sustainable Development, 26(1), 18-33. https://doi.org/10.1002/sd.1688

Hahn, J., \& Andor, L. (2013). Guide to Social Innovation. Brussels: European Commission. Recuperado em 15 setembro, 2019, de https://ec.europa.eu/eip/ ageing/library/guide-social-innovation_en

Hansmann, R., Mieg, H. A., \& Frischknecht, P. (2012). Principal sustainability components: Empirical analysis of synergies between the three pillars of sustainability. International Journal of Sustainable Development and World Ecology, 19(5), 451-459. https://doi.org/10.1080/13504509.2012.696220

Hervieux, C., \& Voltan, A. (2019). Toward a systems approach to social impact assessment. Social Enterprise Journal, 15(2), 264-286. https://doi.org/10.1108/ SEJ-09-2018-0060 
Howaldt, Juergen, \& Schwarz, M. (2017). Social innovation and human development how the capabilities approach and social innovation theory mutually support each other. Journal of Human Development and Capabilities, 18(2), 163-180. https://doi. org/10.1080/19452829.2016.1251401

Howaldt, J., Domanski, D., \& Kaletka, C. (2016). Social Innovation: towards a new innovation paradigm. RAM. Revista de Administração Mackenzie, 17(6), 20-44.

Howaldt, Jürgen, \& Schwarz, M. (2016). Social innovation and its relationship to social change. Verifying existing Social Theories in reference to Social Innovation and its Relationship to Social change. (Research Report №. 612870). Recuperado em 15 setembro, 2019, de http://www.sfs.tu-dortmund.de/cms/Medienpool/small_ publications/SI-DRIVE_D1-3-Social-Change_final-260416.pdf

Howard, L. (2019). Sustainable consumption: key issues. Local Environment, 24(3), 310-311. https://doi.org/10.1080/13549839.2018.1555580

Instituto Banco Palmas (2019). Como implantar um banco comunitário. Recuperado em 15 setembro, 2019, de http://www.institutobancopalmas.org/como-implantarum-banco-comunitario

Jackson, T. (2007). 16 Sustainable consumption. In G. Atkinson, S. Dietz \& E. Neumayer (Eds.). Handbook of Sustainable Development (Cap. 4, pp.254-268). Cheltenham: Edward Elgar Publishing.

Jackson, T., \& Michaelis, L. (2003). Policies for sustainable consumption. A report to the Sustainable Development Commission. Recuperado em 15 setembro, 2019, de https://research-repository.st-andrews.ac.uk/bitstream/handle/10023/2237/sdc2003-consumption-policy.pdf

Jaeger-Erben, M., John, R., \& Ruckert-John, J. (2017). Social innovation: promise or seduction? Response to J. Howaldt and M. Schwarz in GAIA 26/3 (2017): capturing the mechanisms of transformative change. Plea for a practical theoretical concept of social innovations. Gaia-Ecological Perspectives for Science and Society, 26(3), 245-248. https://doi.org/10.14512/gaia.26.3.7

Jaeger-Erben, M., Rueckert-John, J., \& Schaefer, M. (2015). Sustainable consumption through social innovation: a typology of innovations for sustainable consumption practices. Journal of Cleaner Production, 108, 784-798. https://doi.org/10.1016/j. jclepro.2015.07.042

Kaya Özbag, G., Esen, M., \& Esen, D. (2019). Bibliometric analysis of studies on social innovation. International Journal of Contemporary Economics and Administrative Sciences, 9(1), 25-45. https://doi.org/10.5281/zenodo.3262221

Kiss, G., Pataki, G., Koves, A., \& Kiraly, G. (2018). Framing sustainable consumption in different ways: policy lessons from two participatory systems mapping exercises in Hungary. Journal of Consumer Policy, 41(1), 1-19. https://doi.org/10.1007/s10603017-9363-y

Klein, J. L., Fontan, J. M., Harrisson, D., \& Lévesque, B. (2012). The Quebec system of social innovation: a focused analysis on the local development field. FinisterraRevista Portuguesa de Geografia, 94, 9-28.

Larrinaga, O. V. (2017). Is it desirable, necessary and possible to perform research using case studies? Cuadernos de Gestión, 17(1), 147-171.

Lorek, S., \& Spangenberg, J. H. (2014). Sustainable consumption within a sustainable economy beyond green growth and green economies. Journal of Cleaner Production, 63, 33-44. https://doi.org/10.1016/j.jclepro.2013.08.045 
Luskin, J., \& Del Matto, T. (2007). Introduction to the special issue on sustainable production and consumption: making the connection. Journal of Cleaner Production, 6(15), 489-491.

Mehmood, A., \& Parra, C. (2013). Social innovation in an unsustainable world. In F. Moulaert, D. MacCallum, A. Mehmood \& A. Hamdouch, (Eds.). The international handbook on social innovation: collective action, social learning and transdisciplinary research, (Cap 4, pp. 53-66.) Cheltenham: Edward Elgar.

Melo Neto, J. J., \& Magalhães, S. (2007). Bairros pobres, ricas soluções: Banco Palmas, ponto a ponto. Fortaleza: Expressão Gráfica.

Mont, O., Neuvonen, A., \& Lähteenoja, S. (2014). Sustainable lifestyles 2050: stakeholder visions, emerging practices and future research. Journal of Cleaner Production, 63, 24-32.

Moulaert, F., MacCallum, D., Mehmood, A., Hamdouch, A., Hillier, J., \& Beinstein, B. (2010). Social innovation: collective action, social learning and transdisciplinary research. (Research Report N. 29044). Recuperado em 15 setembro, 2019, de https://pt.scribd.com/document/394191842/Social-Innovation-Collective-actionsocial-learning-and-transdisciplinary-research

Moulaert, F., Martinelli, F., Gonzalez, S., \& Swyngedouw, E. (2007). Introduction: social innovation and governance in European cities: urban development between path dependency and radical innovation. European Urban and Regional Studies, 14(3), 195-209. https://doi.org/10.1177/0969776407077737

Mulgan, G., Tucker, S., Ali, R., \& Sanders, B. (2007). Social innovation: what it is, why it matters and how it can be accelerated. London: The Young Foundation.

Murray, R., Caulier-Grice, J., \& Mulgan, G. (2010). The open book of social innovation. London: Young Foundation, National Endowment for Science, Technology and the Arts NESTA.

Nunes, N. A., Casagrande, J. L., Ramos, M. M. G., Santos, A. A. P., \& Corseuil, L. (2017). Community participation as a social innovation practice: a case study at the Marist Educational Center Lucia Mayvorne. Revista Eletronica de Estrategia e Negocios - Reen, 10(2), 154-180. https://doi.org/10.19177/reen.v10e22017154-180

Oliveira, V. M., Gomez, C. R. P., \& Correia, S. É. N. (2018). Os papéis da sociedade civil como protagonista no processo de promoção do consumo sustentável: uma análise baseada na percepção de especialistas brasileiros. Organizações \& Sociedade, 25(85), 229-246.

Oliveira, B. M. A. (2019). A (r)evolução das moedas sociais: do palmacard ao e-dinheiro. Recuperado em 15 setembro, 2019, de https://www.institutobancopalmas.org/arevolucao-das-moedas-sociais-do-palmacard-ao-e-dinheiro/

Pel, B., Wallenborn, G., \& Bauler, T. (2016). Emergent transformation games: exploring social innovation agency and activation through the case of the Belgian electricity blackout threat. Ecology and Society, 21(2), 17. https://doi.org/10.5751/ ES-08346-210217

Phipps, M., Ozanne, L. K., Luchs, M. G., Subrahmanyan, S., Kapitan, S., Catlin, J. R., Gau, R., Naylor, R. W., Rose, R. L., Simpson, B., \& Weaver, T. (2013). Understanding the inherent complexity of sustainable consumption: a social cognitive framework. Journal of Business Research, 66(8), 1227-1234. https://doi.org/10.1016/j.jbusres.2012.08.016

Piccarozzi, M. (2017). Does social innovation contribute to sustainability? The case of Italian innovative start-ups. Sustainability (Switzerland), 9(12), 2-28. https://doi. org/10.3390/su9122376 
Quoquab, F., \& Mohammad, J. (2017). Managing sustainable consumption: is it a problem or panacea? 115-125. https://doi.org/10.1007/978-3-319-45081-0_7

Quoquab, F., Mohammad, J., \& Sukari, N. N. (2019). A multiple-item scale for measuring "sustainable consumption behaviour" construct: development and psychometric evaluation. Asia Pacific Journal of Marketing and Logistics, 31(4) https://doi.org/10.1108/APJML-02-2018-0047

Reisch, L. A., Cohen, M. J., Thogersen, J. B., \& Tukker, A. (2016). Frontiers in sustainable consumption research. Gaia-Ecological Perspectives for Science and Society, 25(4), 234-240. https://doi.org/10.14512/gaia.25.4.4

Rigo, A. S., \& França Filho, G. C. (2017). Bancos comunitários e moedas sociais no Brasil: Reflexões a partir da noção de economia substantiva. Salvador: EDUFBA.

Rollin, J., \& Vincent, V. (2007). Acteurs et processus d'innovation sociale au Québec. Recuperado em 15 setembro, 2019, de http://www.rqis.org/wp-content/ uploads/2015/09/Acteurs-et-processus-dinnovation-sociale-au-Qu\%C3\%A9bec.pdf

Saldaña, J. (2013). The Coding Manual for Qualitative Researchers. London: Sage.

Sampieri, R. H., Collado, C. F., \& Lucio, P. B. (2014). Metodología de la Investigación. México: Mc Graw Hill/Interamericana editores.

Schroder, P., Vergragt, P., Brown, H. S., Dendler, L., Gorenflo, N., Matus, K., Quist, J., Rupprecht, C. D. D., Tukker, A., \& Wennersten, R. (2019). Advancing sustainable consumption and production in cities: a transdisciplinary research and stakeholder engagement framework to address consumption-based emissions and impacts. Journal of Cleaner Production, 213, 114-125. https://doi.org/10.1016/j. jclepro.2018.12.050

Serpa, E. (2018). Mulheres dominam o crédito do Banco Palmas, no conjunto Palmeiras. Diário do Nordeste, Ceará. Recuperado em 24 agosto, 2018, de http:// blogs.diariodonordeste.com.br/egidio/mulheres-dominam-o-credito-do-bancopalmas-no-conjunto-palmeiras/.

Seyfang, G. (2007). Cultivating carrots and community: local organic food and sustainable consumption. Environmental Values, 16(1), 105-123. https://doi. org/10.3197/096327107780160346

Seyfang, G. (2010). Community action for sustainable housing: building a lowcarbon future. Energy Policy, 38(12), 7624-7633. https://doi.org/10.1016/j. enpol.2009.10.027

Seyfang, G., \& Longhurst, N. (2013). Growing green money? Mapping community currencies for sustainable development. Ecological Economics, 86(C), 65-77.

Tardif, C., \& Harrisson, D. (2005). Complémentarité, convergence et transversalité: la conceptualisation de l'innovation sociale au CRISES. Centre de Recherche Sur Les Innovations Sociales Cahiers du CRISES. Recuperado em 15 setembro, 2019, de https://depot.erudit.org/bitstream/001601dd/1/ET0513.pdf

Tukker, A., Emmert, S., Charter, M., Vezzoli, C., Sto, E., Andersen, M. M., Geerken, T., Tischner, U., \& Lahlou, S. (2008). Fostering change to sustainable consumption and production: an evidence-based view. Journal of Cleaner Production, 16(11), 1218-1225. https://doi.org/10.1016/j.jclepro.2007.08.015

Vinuto, J. (2014). A amostragem em bola de neve na pesquisa qualitativa: um debate em aberto. Temáticas, 22(44), 203-220.

Yin, R. K. (2016). Pesquisa qualitativa do início ao fim. Porto Alegre: Penso Editora. 